\title{
Formal and Informal Risk Sharing in LDCs: Theory and Empirical Evidence
}

\author{
Pierre Dubois*, Bruno Jullien†, Thierry Magnac ${ }^{\ddagger}$
}

First version: February 2004

This version: December 2007

\begin{abstract}
We develop and estimate a model of dynamic interactions in which commitment is limited and contracts are incomplete to explain the patterns of income and consumption growth in village economies of less developed countries. Households can insure each other through both formal contracts and informal agreements, that is, self-enforcing agreements specifying voluntary transfers. This theoretical setting nests the case of complete markets and the case where only informal agreements are available. We derive a system of nonlinear equations for income and consumption growth. A key prediction of our model is that both variables are affected by lagged consumption as a consequence of the interplay of formal and informal contracting possibilities. In a semi-parametric setting, we prove identification, derive testable restrictions and estimate the model with the use of data from Pakistan villages. Empirical results are consistent with the economic arguments. Incentive constraints due to self-enforcement bind with positive probability and formal contracts are used to reduce this probability.
\end{abstract}

JEL Classification: C14, D13, D91, L14, O12

Key Words: Risk sharing, Contracts, Incomplete Markets, Informal Transfers

\footnotetext{
*Toulouse School of Economics (GREMAQ \& IDEI \& INRA), (dubois@toulouse.inra.fr).

†Toulouse School of Economics (GREMAQ \& IDEI), (bjullien@cict.fr).

†Toulouse School of Economics (GREMAQ \& IDEI), (magnac@cict.fr).
} 


\section{Introduction ${ }^{1}$}

Limited commitment is an attractive way of accommodating consistent empirical evidence that full-risk sharing is rejected in village economies. In this paper, we nest complete markets and limited commitment in a unified set-up. In the context of risk sharing, we show the empirical relevance of the joint consideration of incomplete markets and dynamic interactions using household data from villages in Pakistan.

Limited commitment refers to situations in which there is no legal contract enforceability (Thomas and Worrall, 1988). Some level of insurance can nonetheless be achieved through informal agreements between agents engaged in a long-term relationship. These agreements take the form of voluntary transfers that are self-enforcing in a game theoretic sense. Parties abide by the informal agreement because they anticipate that defection would result in the breakdown of future profitable informal agreements. The existing literature has contrasted setttings with a complete market structure and settings in which all agreements are informal. Yet, real institutions, and in particular village institutions, usually involve a mix of formal and informal agreements. Indeed, village institutions may be able to enforce specific types of formal contracts like sharecropping or other land-leasing contracts even if a complete market structure is beyond reach.

In this paper we propose a model of risk sharing that allows for two types of transactions between agents - voluntary transfers and formal contracts. A distinguishing feature is the focus on the interaction between contracts and informal agreements. Informal agreements can, not only specify voluntary transfers in various states of nature but also which contracts should be signed and when. As a consequence, all observed decisions in equilibrium are part of informal agreements including formal contracts. Formal contracting, instead of expanding the set of feasible transfers, serves to expand the set of incentive compatible allocations by allowing parties to use them as an enforcement tool for voluntary transfers. To some extent, formal contracts are used as collateral in informal lending-borrowing agreements in a risk sharing context. Individuals receiving a large transfer - because of negative income shocks, for instance - should, in exchange, concede more favorable terms on the formal contracts, raising the future prospects of the other party. The existence of formal contracting relaxes incentive constraints due to limited commitment and improves global efficiency.

\footnotetext{
${ }^{1}$ We thank IFPRI for providing us with the data. We are indebted to Fabien Postel-Vinay for very detailed comments. We thank the co-editor and three referees for their comments, Orazio Attanasio, Richard Blundell, Andrew Foster, Patrick Gonzalez, Stéphane Grégoir, Ethan Ligon, Thomas Mariotti, Mark Rosenzweig, Bernard Salanié, Mike Whinston and Tim Worall for discussions, and participants at seminars at Toulouse, CREST, Bristol, Southampton, University College of London, Montréal, Laval University, Cergy, Namur, CEMFI, IZA, Mannheim, Alicante, Munich and Yale and conferences (Jean Jacques Laffont'05, WCES'05 London, SBE'05 Natal, ASSET'06, Lisbon) for their helpful comments. The usual disclaimer applies.
} 
Another key contribution of this paper is the econometric and empirical implementation using data from village economies in Pakistan which shows that our theoretical model is an empirically credible alternative. We do more than simply test the alternatives of complete markets, limited commitment and the mix of formal and informal contracts. We exhibit the conditions under which the model is semi-parametrically identified, derive its testable implications and test them.

Contract enforcement depends on specific institutions within each village and evaluating their degree of formality is a difficult task. This motivates us to work within the set-up of Deaton (1997) in that we do not examine specific institutions in villages but the consequences they have on household behavior in terms of the dynamics of income and consumption. To this end, we exploit the rich dynamics that our setting generates. We characterize the dynamics of household consumption and income by showing that these processes are functions of a state variable which is the relative marginal utility of consumption of the household with respect to the village. The process of this state variable retains a rich memory of the past in contrast to the limited commitment case in which once an incentive compatibility constraint is binding, all the past becomes irrelevant. Household relative marginal utility is a random walk with jumps (as in the limited commitment case of Ligon, Thomas and Worrall, 2002) although the occurrence and size of jumps are not exogenous and depend on the relative marginal utility in the previous period.

Our paper builds upon a rich empirical and theoretical literature on village economies in LDCs. Starting with the seminal paper of Townsend (1994), the empirical evaluation of the complete market hypothesis in village economies has led to a better understanding of market failures and to a better identification of the characteristics of the households that are most affected by these failures (Deaton, 1997, Morduch, 1999, Fafchamps, 2003, Dercon, 2004). In developed countries, the question of interest is also how well agents are insured (Attanasio and Rios-Rull, 2003, Blundell, Pistaferri and Preston, 2003). Regarding theoretical arguments, we specifically use the literature that highlights the issue of contract enforcement and limited commitment in risk sharing (see Thomas and Worrall, 1988, Kocherlakota, 1996). Indeed, village economies lack the institutions needed to enforce contracts and in most villages, there are no written records of transfers such as loans, nor are there proper institutions designed to enforce repayments, which can therefore be delayed or simply canceled. As a consequence, villagers use informal agreements that are Pareto-improving provided they can be self-enforced (Coate and Ravallion, 1993, Fafchamps, 1992). This requirement restricts the set of informal agreements which in turn may not be rich enough to achieve complete risk sharing in the village. A few recent papers show that these arguments are empirically relevant and that self-enforcing transfers play a part in sharing risk within villages (Ligon, Thomas and Worrall, 2000, 2002) and within networks or extended families (Foster and Rosenzweig, 2001). 
Full risk sharing and limited commitment are two polar cases, however. Some institutions might help enforce some formal contracts. Specifically, sharecropping and fixed rent formal contracts are commonly observed in villages of LDCs and their role in allocating risk has been repeatedly emphasized (Stiglitz, 1974, Newbery, 1977). The ability of landlords to enforce contracts on land is a critical issue and the design of such contracts is the subject of many empirical studies (Shaban, 1987). Dubois (2000) provides empirical evidence, using the same data as the present paper, that sharecropping or other land contracts allow risk sharing. Households use these instruments to smooth income as well as consumption (Morduch, 1995). Furthermore, Bell (1988) and Udry (1994) have emphasized that formal contracts are often accompanied by informal transfers that attenuate their effects in bad states of nature. Another branch of literature from which we depart, focuses on the role of asymmetric information (see Thomas and Worrall, 1990, Doepke and Townsend, 2006, and references therein). The issue of formal and informal risk sharing is also of wider importance apart from this specific application, as it is relevant to many other domains including international debt, finance, the internal labor market or social networks.

Outline and main findings In Section 2, we construct and analyze a theoretical model of long-term dynamic interactions between households in which several cases are nested: Complete markets if all risks can be insured by formal contracts; A single non-contingent transfer as in Gauthier, Poitevin and Gonzalez (1997); Limited commitment and no formal contracts as in Ligon et al. (2002). A specific feature is that we embed both income and preference shocks into a two-agent model in which one agent, who ultimately represents the "village" can commit himself while the other agent (the "household") cannot.

The market allocation (consumption, income and contracts) is obtained as an equilibrium of an infinite horizon game. Using recursive methods, we characterize constrained Pareto efficient allocations where an allocation specifies the sequence of contracts and informal transfers to be implemented and which are possibly random to account for non-concavity issues. We then derive optimality conditions and monotone comparative results. Any efficient equilibrium allocation is characterized by two monotone (stochastic) mappings: one maps current consumption into contracts, and the other is an Euler equation in which consumption growth, instead of being a martingale, is affected by lagged consumption and current income.

In Section 3, we specify the econometric model. It involves two equations of interest: the Euler equation of consumption dynamics and an income equation. We derive the testable predictions of our theoretical model using this specification. One such prediction is that income monotonically depends on lagged consumption. Other testable predictions include other monotonicity restrictions as well as parametric restrictions across the income and consumption equations. 
In Section 4, the model is estimated by semi-parametric methods using a panel survey collected in Pakistan by IFPRI at the end of the 1980s. Because of non linearities, we estimate the model of income and consumption growth by penalized splines (Yu and Ruppert, 2002). Results are consistent with the predictions of the theoretical model and, in particular, lagged consumption affects income as predicted. The results hold true in the presence of measurement errors, of superior information that households might have on future income shocks and of nutrition effects on productivity as the two last factors could generate a similar prediction. They are also robust to assumptions about labor market imperfections. Among other results, the estimation of the consumption growth equation leads to an estimate of a lower bound on the probability that a self-enforcing constraint binds. This estimated bound is roughly equal to $15 \%$.

In the last section, we discuss the economic relevance of our empirical results, the limitations of our approach and future research avenues. We conclude by discussing some policy implications. Proofs are in the appendix.

\section{A Theoretical Model of Risk Sharing with Formal and Informal Contracts}

This section presents the theoretical model. We first define preferences, income processes, the contractual environment as well as the timing of the game. Second, we characterize the constrained Pareto optimal allocations. To this end, we define two Bellman equations at the ex-ante and interim stages and discuss their properties. Building on this we propose a characterization of the dynamics of income and consumption processes. Last, we extend the model to account for the presence of observed heterogeneity.

\subsection{The Model}

We consider a two-agent framework and assume full commitment by one agent and none by the other. $^{2}$ Time is discrete and goes from 1 to infinity, $t=1, \ldots, \infty$. Let $s_{t}$ denote a random state of the world at date $t$, identically and independently distributed (i.i.d.) on a finite support $\mathcal{S}$. The extension to a general Markov process is undertaken at the end of the section. State $s$ occurs with probability $p_{s}$, and agent $i$ receives exogenous resources $\omega^{i}(s)$. There is no storage possibility and no financial market.

The utility function of agent 1 is written at date $t \geq 1$ as $u_{t}()=.\eta_{t} u($.$) , where \left(\eta_{t}\right)_{t=1}^{\infty}$ is a random process. In the empirical part, $\eta_{t}$ represents the new information affecting preferences that is revealed at the beginning of a period and that is never observed by the econometrician. In

\footnotetext{
${ }^{2}$ We analyze the two-sided limited commitment case in a companion paper (Dubois, Jullien and Magnac (2002)).
} 
the theoretical part, its presence ensures enough variability in the allocation, implying in particular that the problem is strictly concave and the allocation is uniquely defined with probability 1. Setting $\eta_{0}=1$, we denote $\chi_{t}=\frac{\eta_{t}}{\eta_{t-1}}$ and we follow the literature by assuming that $\chi_{t}$ is i.i.d. on an interval of $\mathbb{R}^{+}$, with mean 1 and positive density.

The second agent has non-stochastic preferences since what matters are ratios of marginal utility between the two agents. Her preferences are described by a Von-Neumann Morgenstern utility function $v($.$) . We assume that u$ and $v$ are concave, twice continuously differentiable, $u(0)=v(0)=0$ and $u^{\prime}(0)=v^{\prime}(0)=+\infty$ and this ensures that consumption levels are positive. Both agents share the same discount rate $\rho$. The ex-ante expected intertemporal utility of agents 1 and 2 are respectively $E\left[\sum_{t=1}^{\infty} \rho^{t-1} u_{t}\left(c_{t}^{1}\right)\right]$ and $E\left[\sum_{t=1}^{\infty} \rho^{t-1} v\left(c_{t}^{2}\right)\right]$.

Because of convexity issues, we allow agents to implement random allocations. To this end, we assume that there is a public random variable, $\varepsilon_{t}$, which is i.i.d. and continuous on a compact support.

The precise timing of realization of the various events within period $t$, is the following.

- Interim stage: At the beginning of period $t$, the shocks $\chi_{t}$ and $\varepsilon_{t}$ are publicly realized. A formal contract is signed.

- Ex-post stage: At the end of period $t$, the income shock $s_{t}$ is publicly realized. The formal contract is enforced. Then parties may complement it by voluntary transfers and consumption takes place.

We shall also consider an ex-ante stage posterior to date $t-1$ consumption but anterior to the realization of date $t$ shocks $\chi_{t}$ and $\varepsilon_{t}$.

Once signed, formal contracts are valid for period $t$ and binding for both agents. They are restricted and incomplete as follows:

1. Contracts are short term, specifying how resources will be shared within the period only.

2. Contracts can be contingent only on the realization of exclusive events $e \in \mathcal{E}$, where $\mathcal{E}$ is a finite partition of the set of states of nature $\mathcal{S}$. An event $e \in \mathcal{E}$ is a subset of $\mathcal{S}$, and occurs with probability $p_{e}=\sum_{s \in e} p_{s}$.

3. Contracts entail real costs, while voluntary transfers involve no real cost. ${ }^{3}$

A contract is represented by a vector $(\tau(e))_{e}$ of net transfers received by agent 1 . Transfers belong to some compact set $\times_{e}[\underline{\tau}(e), \bar{\tau}(e)]$, where $\underline{\tau}(e)<0 \leq \bar{\tau}(e)$. Transferring $\tau$ in event $e$

\footnotetext{
${ }^{3}$ This assumption is necessary to obtain an interior solution with one-sided commitment, it can be dispensed with in the case of bilateral limited commitment (see Dubois et al. , 2002).
} 
through a contract entails a cost $\varphi(e, \tau)$ for agent 2. As a consequence, total resources in state $s \in e$ are $\omega^{1}(s)+\omega^{2}(s)-\varphi(e, \tau(e))$. We assume that $\varphi(e,$.$) is continuously differentiable, quasi-$ convex, with a minimum $\varphi(e, 0)=0$ at $\tau=0$. For conciseness, we also assume that the set of contracts is such that both agents enjoy positive consumption levels in all states. ${ }^{4}$ This could easily be relaxed by assuming that the transfers are set ex-post to the minimum between the formal quantity and the agent's resources (see our working paper, Dubois, Jullien and Magnac, 2005).

When no contract is feasible $(\mathcal{E}=\varnothing)$, we obtain the model of informal risk sharing as in Thomas and Worrall (1988). We obtain the polar case of complete contracting when $\mathcal{E}=\mathcal{S}$ and the cost of transfers is zero, $\varphi \equiv 0$, over the relevant range (and $\underline{\tau}$ is sufficiently negative). Moreover, our setting nests the model of Gauthier, Poitevin and Gonzalez (1997) since, among other things, they consider one ex-ante transfer only $(\mathcal{E}=\{\mathcal{S}\}$ i.e. $\operatorname{card}(\mathcal{E})=1)$.

Denote $H_{t}=\left[\left(s_{r-1}, \chi_{r}, \varepsilon_{r}\right)_{r}\right]_{r=1}^{t}$ the history of shocks up to the beginning of period $t$. An allocation is a random profile of formal transfers $\tau_{t}$ and consumptions $c_{t}^{i}$ that are measurable with respect to the relevant information, i.e. $\tau_{t}=\tau\left(H_{t}, e_{t}\right)$ and $c_{t}^{i}=c^{i}\left(H_{t}, s_{t}\right)$, and that satisfy the resource constraint, for all $H_{t}$ and $s_{t}$ :

$$
c_{t}^{1} \geq 0, c_{t}^{2} \geq 0, \text { and } c_{t}^{1}+c_{t}^{2}=\omega_{t},
$$

where $\omega_{t}=\omega^{1}\left(s_{t}\right)+\omega^{2}\left(s_{t}\right)-\varphi\left(e_{t}, \tau_{t}\right)$ denotes aggregate resources available at date $t$.

\subsection{Intertemporal Payoffs and Feasible Allocations}

In the benchmark case in which financial markets are complete, optimal insurance is achieved and consumption at date $t$ only depends on the realization of aggregate resources that are maximal at $\tau\left(e_{t}\right)=0$. According to Borch's rule, the ratio of marginal utility is the same in all states of nature so that consumption dynamics are characterized by

$$
\eta_{t+1} \frac{u^{\prime}\left(c_{t+1}^{1}\right)}{v^{\prime}\left(c_{t+1}^{2}\right)}=\eta_{t} \frac{u^{\prime}\left(c_{t}^{1}\right)}{v^{\prime}\left(c_{t}^{2}\right)} .
$$

In our set-up there is no financial market, but agent 2 can fully commit to a set of future actions while agent 1 cannot commit at all and at any point in time maximizes his payoff. Any equilibrium allocation must be self-supporting in a game theoretic manner.

Because of the presence of the random parameter $\eta_{t}$, our model is not strictly speaking a repeated game. Yet, it is stationary in the sense that the sub-game starting at date $t$ is identical to the game starting at date 1 provided that the utility levels are re-normalized. To see that,

\footnotetext{
${ }^{4}$ More formally, for all $e, \tau \in[\underline{\tau}(e), \bar{\tau}(e)]$ and $s \in e, \omega^{1}(s)+\tau>0$ and $\omega^{2}(s)-\tau-\varphi(e, \tau)>0$.
} 
define the expected utility at the beginning of date $t$, normalized by $\eta_{t}$ for agent 1 , as:

$$
U_{t}=E\left[u\left(c_{t}^{1}\right)+\sum_{r=1}^{\infty} \rho^{r} \frac{\eta_{t+r}}{\eta_{t}} u\left(c_{t+r}^{1}\right) \mid H_{t}\right], \quad V_{t}=E\left[\sum_{r=0}^{\infty} \rho^{r} v\left(c_{t+r}^{2}\right) \mid H_{t}\right] .
$$

Now consider the subgame starting at date $t$ with $H_{t}$ known. Given that $\frac{\eta_{t+r}}{\eta_{t}}=\Pi_{l=1}^{r} \chi_{t+l}$, the distribution of $\left\{\frac{\eta_{t+r}}{\eta_{t}}, \varepsilon_{t+r}, s_{t+r}\right\}_{r \geq 1}$ is independent of the period $t$; and the subgame starting at date $t>1$ is identical to the initial game. The sets of equilibria of the two games coincide and thus the tools of repeated game theory apply.

Specifically, there are minimum and maximum expected utility levels that can be supported in equilibrium for each agent. Since agent 2 can commit to transfer all her wealth, the minimum level is $\underline{V}=0$. On the other hand agent 1 will reject any proposed agreement leading to a utility level $U_{t}$ below the autarky level:

$$
\underline{U}=\frac{1}{1-\rho} \sum_{s} p_{s} u\left(\omega^{1}(s)\right)
$$

Since agent 2 can commit not to contract at all with agent $1, \underline{U}$ is indeed the minimum utility that he can obtain.

In order to prevent agent 1 from reneging on the agreement, it is optimal to coordinate in such a way that if he deviates, the equilibrium that follows is the worst equilibrium for him. In other words one should apply an optimal penal code as defined by Abreu (1988): An allocation can be supported in equilibrium provided that, at any point in time, agent 1 prefers to abide by the informal agreement rather than to renege and be punished by receiving his minimum equilibrium expected utility. Thus at date $t$, agent 1 should be willing to sign the formal contract at the interim stage,

$$
U_{t} \geq \underline{U}
$$

Once $s_{t}$ is realized, at the ex-post stage, agent 1 must also prefer to make the informal transfer rather than to enforce the formal contract only and continue in autarky next period:

$$
u\left(c_{t}^{1}\right)+\rho E\left[\chi_{t+1} U_{t+1} \mid H_{t}, s_{t}\right] \geq u\left(\omega_{t}^{1}+\tau_{t}\right)+\rho \underline{U} .
$$

In conclusion, the set $\mathcal{F}$ of allocations that satisfy the resource constraint (1), the participation constraint (3) and the incentive compatibility condition (4) at all dates and all histories is the set of feasible allocations.

\subsection{Value Functions and Bellman Equations}

Our goal is to derive the set of constrained Pareto optimal allocations. An allocation is optimal if agent 1 receives the largest possible expected utility given agent 2's expected utility among 
the feasible allocations. This set, or frontier, can be evaluated at various stages. It will be useful to consider two stages: before any shock is revealed, the ex-ante definition, or after revelation of the shocks $(\chi$ and $\varepsilon$ ) at the beginning of the period, the interim definition.

Definition 1 At the interim stage, when $H_{1}=\left(\chi_{1}, \varepsilon_{1}\right)$ is known, the Pareto frontier is the set of feasible interim utility $(P(V), V)$ characterized by the interim value function:

$$
P(V)=\max _{\left(c_{t}^{1}, c_{t}^{2}, \tau_{t}\right)_{t=1}^{\infty} \in \mathcal{F}} U_{1} \text { s.t. } \quad V_{1} \geq V
$$

where $U_{1}$ and $V_{1}$ are date 1 normalized utility levels for agents 1 and 2 defined in equation (2).

Definition 2 At the ex-ante stage, the Pareto frontier is the set of feasible ex-ante utility $(Q(V), V)$ characterized by the ex-ante value function:

$$
Q(V)=\max _{\left(c_{t}^{1}, c_{t}^{2}, \tau_{t}\right)_{t=1}^{\infty} \in \mathcal{F}} E\left[\chi_{1} U_{1}\right] \quad \text { s.t. } E\left[V_{1}\right] \geq V
$$

where the expectation operator refers to the joint distribution of $\left(\chi_{1}, \varepsilon_{1}\right)$.

Optimality implies that at any date the allocation remains optimal conditional on history provided that agent 1 has not deviated. Thus, given stationarity, $U_{t}=P\left(V_{t}\right)$ with probability 1 .

Moreover, the interim and the ex-ante frontier are linked by the relation $Q\left(E\left[V_{1}\right]\right)=E \chi_{1} P\left(V_{1}\right)$. Denote $F\left(. \mid \chi_{1}\right)$ the marginal distribution of date 1 utility $V_{1}$ conditional on the realization of the random shock $\chi_{1}$ only. With the use of the random component $\varepsilon_{1}$, it is possible to implement any distribution on support $[\underline{V}, \bar{V}]$, so that $Q(V)$ is the solution of the ex-ante Bellman equation

$$
Q(V)=\max _{\left\{F\left(. \mid \chi_{1}\right)\right\}} E\left[\int_{\underline{V}}^{\bar{V}} \chi_{1} P\left(V_{1}\right) d F\left(V_{1} \mid \chi_{1}\right)\right] \text { s.t. } E\left[\int_{\underline{V}}^{\bar{V}} V_{1} d F\left(V_{1} \mid \chi_{1}\right)\right] \geq V
$$

where the expectation operator refers to the distribution of $\chi_{1}$.

Again optimality implies that at any date:

$$
E\left(\chi_{t} U_{t} \mid H_{t-1}, s_{t-1}\right)=Q\left(E\left(V_{t} \mid H_{t-1}, s_{t-1}\right)\right),
$$

with probability 1 . Notice that, using $\eta_{t+1}=\chi_{t+1} \eta_{t}$ :

$$
U_{t}=E\left[u\left(c_{t}^{1}\right)+\rho \chi_{t+1} U_{t+1} \mid H_{t}\right], \quad V_{t}=E\left[v\left(c_{t}^{2}\right)+\rho V_{t+1} \mid H_{t}\right]
$$

Therefore, equation (6) implies that the solution of the interim program is such that:

$$
U_{t}=E\left[u\left(c_{t}^{1}\right)+\rho Q\left(E\left(V_{t+1} \mid H_{t}, s_{t}\right)\right) \mid H_{t}\right]
$$


Combining this with $U_{t}=P\left(V_{t}\right)$ allows us to write the value function $P($.$) the solution to the$ interim Bellman equation:

$$
\begin{aligned}
& P(V)=\max _{\left(c^{1}(s), c^{2}(s), V(s)\right)_{s},(\tau(e))_{e}} \sum_{s \in \mathcal{S}} p_{s}\left[u\left(c^{1}(s)\right)+\rho Q(V(s))\right] \\
& \text { s.t } \quad \sum_{s \in \mathcal{S}} p_{s}\left[v\left(c^{2}(s)\right)+\rho V(s)\right] \geq V \\
& u\left(c^{1}(s)\right)+\rho Q(V(s)) \geq u\left(\omega^{1}(s)+\tau(e)\right)+\rho \underline{U} \quad \forall e \in \mathcal{E}, \forall s \in e \\
& c^{1}(s)+c^{2}(s)=\omega^{1}(s)+\omega^{2}(s)-\varphi(e, \tau(e)) \quad \forall e \in \mathcal{E}, \forall s \in e \\
& 0=\underline{V} \leq V(s) \leq \bar{V} \quad \forall s \in \mathcal{S}
\end{aligned}
$$

where the participation constraint (3) is embedded in constraint (12).

The solution to the interim Bellman equation (8) maps utility $V_{t}$ into a formal transfer $\tau_{t}$, consumption levels $c_{t}^{i}$ and continuation expected utility at the end of period $t$ contingent on the realization of the shock $s_{t}$. Moreover, the solution of the ex-ante Bellman equation (5) characterizes the distribution of period $t+1$ utility $V_{t+1}$ as a function of the expected utility promised at the end of period $t$ and of the shock $\chi_{t+1}$.

Using the argument of Thomas and Worrall (1988), the value functions $Q(V)$ and $P(V)$ are decreasing and continuous on the interval $[\underline{V}, \bar{V}]$. We however need to address concavity and differentiability issues.

\subsubsection{Properties of the interim value function}

Consider the interim value function $P$. Since $Q$ is concave, the program defining $P$ is concave for a fixed contract $(\tau(e))_{e}$. However, when the contract is optimally designed, $P($.$) may not be$ concave or differentiable. Let $\hat{P}($.$) be the convex hull of P($.$) :$

$$
\hat{P}(V)=\max _{F \in \Delta[\underline{V}, \bar{V}]} \int_{\underline{V}}^{\bar{V}} P(w) d F(w) \text { s.t. } \int_{\underline{V}}^{\bar{V}} w d F(w) \geq V .
$$

where $F$ is a distribution on $[\underline{V}, \bar{V}]$. It is the distribution of $V_{t}$ conditional on $\left(H_{t-1}, s_{t-1}, \eta_{t}\right)$, i.e. after realization of the shock $\eta_{t}$ but before randomization.

$\hat{P}(V)$ is a concave and decreasing function. The argument of Benveniste and Scheinkman (1979) can then be adapted along the line of Koeppl (2006) to show that because the incentive constraint cannot bind in all states, $\hat{P}(V)$ is differentiable at $V<\bar{V}$ (Lemma 8 in Appendix). Furthermore, as the agents can randomize over $V_{t}, P\left(V_{t}\right)=\hat{P}\left(V_{t}\right)$ with probability 1 at an optimal allocation. Moreover,

$$
\hat{P}^{\prime}\left(E\left[V_{t} \mid H_{t-1}, s_{t-1}, \chi_{t}\right]\right)=P^{\prime}\left(V_{t}\right)
$$


whenever $V_{t}<\bar{V}$ (notice that $0=\underline{V}<V_{t}$ ). Thus $P$ is differentiable with probability 1 over the support of any optimal allocation.

The equality $P\left(V_{t}\right)=\hat{P}\left(V_{t}\right)$ has another consequence. As $\hat{P}$ is concave, duality theory yields a relationship between the slope of the interim Pareto frontier and the interim utility of agent 2.

Lemma 3 There exists a random variable $\mu_{t}=-\hat{P}^{\prime}\left(V_{t}\right)$, measurable with respect to history $H_{t}$, such that with probability 1 :

$$
V_{t} \in \arg \max _{V \in[\underline{\underline{V}}, \bar{V}]}\left\{P(V)+\mu_{t} V\right\} .
$$

Proof. We have $V_{t} \in \arg \max _{V}\left\{\hat{P}(V)-\hat{P}^{\prime}\left(V_{t}\right) V\right\}$ since $\hat{P}($.$) is concave. Using \hat{P}($. $P\left(\right.$.), we obtain that when $P\left(V_{t}\right)=\hat{P}\left(V_{t}\right)$ then $V_{t} \in \arg \max _{V}\left\{P(V)-\hat{P}^{\prime}\left(V_{t}\right) V\right\}$. The result then follows from $\operatorname{Pr}\left\{P\left(V_{t}\right)=\hat{P}\left(V_{t}\right)\right\}=1$

The lemma implies that characterizing the set of optimal utility $V_{t}$ amounts to characterizing the solutions of program (14) for various values of $\mu_{t}$. In what follows, we describe the dynamics using the Pareto weight $\mu_{t}$ instead of $V_{t}$.

\subsubsection{Properties of the ex-ante value function}

Consider now the ex-ante value function $Q$. Since the program is linear, the ex-ante value function $Q$ is concave, and, as $\hat{P}$, is differentiable. In addition, we show in Lemma 9 (Appendix) that function $Q($.$) is strictly concave thanks to the random effect \chi_{1}$.

$>$ From above, we must have $E\left(U_{1} \mid \chi_{1}\right)=\hat{P}\left(E\left(V_{1} \mid \chi_{1}\right)\right)$ at date 1. Denoting the set of measurable functions from the support of $\chi_{1}$ into $[\underline{V}, \bar{V}]$ by $\mathcal{B}$, the solutions of the ex-ante Bellman equation (5) can be written as

$$
Q(V)=\max _{\hat{V}(.) \in \mathcal{B}} E\left[\chi_{1} \hat{P}\left(\hat{V}\left(\chi_{1}\right)\right)\right] \text { s.t. } E\left[\hat{V}\left(\chi_{1}\right)\right] \geq V,
$$

which determines the choice $E\left[V_{1} \mid \chi_{1}\right]=\hat{V}\left(\chi_{1}\right)$ for a given $V$ and shock $\chi_{1}$. More generally $\hat{V}\left(\chi_{t}\right)$ is the choice of $E\left[V_{t} \mid H_{t-1}, s_{t-1}, \chi_{t}\right]$ as a function of $V=E\left[V_{t} \mid H_{t-1}, s_{t-1}\right]$ and $\chi_{t}$.

The ex-ante and the interim value function are thus linked by optimality conditions implying that at $\hat{V}(\chi)<\bar{V}$ solution to program (15), it must be the case that $Q^{\prime}(V)=\chi_{1} \hat{P}^{\prime}\left(\hat{V}\left(\chi_{1}\right)\right)$. Thus the slopes of the two value functions are linked by the relationship $Q^{\prime}\left(E\left[V_{t} \mid H_{t-1}, s_{t-1}\right]\right)=$ $\chi_{t} \hat{P}^{\prime}\left(V_{t}\right)$. Combined with (13), this provides a first relation between the ex-ante and interim slopes of the Pareto frontiers at an optimal allocation:

$$
Q^{\prime}\left(E\left[V_{t} \mid H_{t-1}, s_{t-1}\right]\right)=\chi_{t} P^{\prime}\left(V_{t}\right) \text { when } V_{t}<\bar{V}
$$

This expression is used below to describe how the (ex-ante) value anticipated at the end of period $t-1$ is transformed into an (interim) expected value at the beginning of period $t$. A recursive 
characterization of an optimal allocation then consists in equation (16) and for any interim value $V_{t}$, a description of the contract, current period consumption levels and the next period ex-ante value as a function of realized shocks.

\subsection{Dynamic Characterization}

The characterization of the dynamics is obtained in several stages. The starting point uses equation (16) above, relating the slopes of the ex-ante and the interim value functions. Suppose that we know from past history the slope of the ex-ante value function $Q_{t}^{\prime}$. Then we can infer the slope of the interim value function

$$
\mu_{t}=P^{\prime}\left(V_{t}\right)=\frac{Q_{t}^{\prime}}{\chi_{t}}
$$

The next step consists in characterizing date $t$ allocation as a function of the slope $\mu_{t}$. This is done by solving the program (14) defining the interim frontier, i.e. by maximizing $P(V)+\mu_{t} V$. This amounts to solve the program given by the interim Bellman equation (8). As part of the characterization we obtain the slope of the next period ex-ante value $Q_{t+1}^{\prime}$. We can then start the process again to obtain a recursive characterization.

The solution to the interim Belman equation

$$
\max _{\left(c^{1}(s), c^{2}(s), V(s)\right)_{s},(\tau(e))_{e}} \sum_{s \in \mathcal{S}} p_{s}\left[u\left(c^{1}(s)\right)+\rho Q(V(s))\right]+\mu_{t} \sum_{s \in \mathcal{S}} p_{s}\left[v\left(c^{2}(s)\right)+\rho V(s)\right]
$$

subject to the incentive compatibility condition (10), the resource constraint (11) and the participation constraint (12), is solved in two stages.

In a first stage we fix the contract $(\tau(e))_{e}$ and the weight $\mu_{t}$ of agent $2^{\prime} s$ utility, and we characterize the solution $\left(c^{1}(s), c^{2}(s), V(s)\right)_{s}$. The benefit of doing so is that the reduced program is concave. This determines date $t$ promised consumption levels and continuation utility for a given contract $(\tau(e))_{e}$ and $\mu_{t}$. A simple arbitrage condition shows that

$$
\frac{u^{\prime}\left(c^{1}(s)\right)}{v^{\prime}\left(c^{2}(s)\right)}=-Q^{\prime}(V(s))
$$

This corresponds to a risk sharing rule which determines the allocation in state $s$ and which trades off consumption and continuation utility.

Moreover, in all states in which agent 1's incentive compatibility condition (10) is not binding, we have $-Q^{\prime}(V(s))=\mu_{t}$, which equates the ratios of marginal utility across states, as required by Borch's rule. However, when agent 1's income is (too) large, maintaining the ratio of marginal utility at $\mu_{t}$ violates incentive compatibility. The future utility allocated to agent 1 must be increased to the level that he would obtain by reneging on the promise and enforcing the contract 
$\tau(e)$. In this case the allocation depends on the resources available and on the outside option, but not on the weight $\mu_{t}$.

In a second stage, we consider the choice of the formal contract for a given weight $\mu_{t}$. Although a full characterization is out of reach, a super-modularity argument shows that the contract is a monotonic function of the Pareto weight. As we move along the frontier $P(V)$ toward higher absolute slopes $\mu$ (and thus higher $V$ ), the contract becomes uniformly less favorable to agent 1 .

The next proposition summarizes the results:

Proposition 4 Denote $\pi_{t}=\omega_{t}^{1}+\tau_{t}$ agent 1's income at date $t$. There exist a function $\bar{\mu}(\omega, \pi)$ with values in $\left(-\hat{P}^{\prime}(\bar{V}),+\infty\right)$, and a correspondence $\bar{T}(\mu)$, with values in $\times_{e}(\underline{\tau}(e), 0]$ such that an optimal allocation satisfies:

i)

$$
\begin{aligned}
\left(\tau_{t}(e)\right)_{e} & \in \bar{T}\left(\mu_{t}\right) \\
\frac{u^{\prime}\left(c_{t}^{1}\right)}{v^{\prime}\left(c_{t}^{2}\right)} & =\min \left\{\mu_{t}, \bar{\mu}\left(\omega_{t}, \pi_{t}\right)\right\} \\
\mu_{t+1} & =\frac{1}{\chi_{t+1}} \frac{u^{\prime}\left(c_{t}^{1}\right)}{v^{\prime}\left(c_{t}^{2}\right)} \text { if } V_{t+1}<\bar{V}
\end{aligned}
$$

ii) $\bar{\mu}(\omega, \pi)$ is decreasing in $\pi$;

iii) $\bar{T}(\mu)$ is non-increasing according to the strong order set. ${ }^{5}$

iv) $\bar{T}\left(\mu_{t}\right)$ is single-valued with probability 1.

For a given formal contract, this proposition is a generalization of Thomas and Worrall (1988) in which one agent is risk neutral and no formal contract is allowed. When agent $1^{\prime} s$ resources are large or the weight put on agent 2 is large, incentive compatibility and efficient risk sharing are conflicting. This is resolved in two ways. First, the consumption profile of agent 1 that follows such a state is shifted upwards. Second, the problem can be alleviated ex-ante by using the formal contract. As the utility $V$ of agent 2 increases, it becomes more difficult to maintain the incentives of agent 1 . Formal contracts are thus more extensively used.

The dynamics can be described by means of the evolution of the weight $\mu_{t}$ associated with the utility $V_{t}$ chosen after history $H_{t}$. At this stage, agents sign a contract $\left(\tau_{t}(e)\right)_{e} \in \bar{T}\left(\mu_{t}\right)$. Consumption is given as a function of $\mu_{t}$, the transfer $\tau_{t}$ and the state of nature $s_{t}$. This also defines the slope $Q^{\prime}\left(E\left(V_{t+1} \mid H_{t}, s_{t}\right)\right)$ at the end of period $t$. Then, at date $t+1, H_{t+1}$ is realized and condition (16) gives the new value of the weight $\mu_{t+1}$.

\footnotetext{
${ }^{5}$ The transfer is strictly decreasing in all events such that the incentive constraint binds with a positive probability and income is positive in some state. If the incentive constraint doesn't bind in all states of event $e$, then the transfer is $\tau(e)=0$.
} 
Whenever the Pareto frontier is locally strictly concave, $\bar{T}(\mu)$ is single valued so that the proposition completely characterizes the dynamics. If $P($.$) is not strictly concave \bar{T}(\mu)$ can be multi-valued. Notice that it is single valued for all values $\mu_{t}$ for which program (14) has a unique solution, i.e. for which $-\hat{P}^{\prime}\left(V_{t}\right)=\mu_{t}$ has a unique solution $V_{t}$. It is shown in Lemma 9 (Appendix) that this occurs with probability 1 due to the effect of the shock $\eta_{t}$. Thus in equilibrium $\bar{T}\left(\mu_{t}\right)$ is single valued with probability 1.

When there is no formal contract, the variable $\bar{\mu}\left(\omega_{t}, \pi_{t}\right)$ is exogenous. The dynamics of consumption after a date $t$ when the incentive constraint binds is independent of past history and depends only on state $s_{t}$. Introducing the possibility of formal contracts dramatically changes this conclusion. Indeed the resources of the agent depend on past history of shocks through the contract $T_{t}$, even after a period in which the incentive constraint binds. Notice that the proposition implies that income $\pi_{t}$ is monotonic in the parameter $\mu_{t}$.

Corollary 5 Income $\pi_{t}$ is non-increasing with $\mu_{t}$ in all states $s_{t}$.

Proof. Condition $i i i$ ) implies that transfer $\tau_{t}$ doesn't increase in all events when $\mu_{t}$ increases. Thus income is uniformly non-increasing.

The same conclusion holds for the allocation of consumption levels and future utility $\left(c_{t}^{1}, U_{t+1}\right){ }^{6}$ Notice also that if there were no shock $\eta_{t}$, the weight $\mu_{t}$ would be decreasing over time. It would converge to some fixed value and the contract should eventually be backloaded in favor of the agent who cannot commit. But due to the shock $\eta_{t}$, there is a positive probability that $\mu_{t}$ increases. Thus starting from any point, there is a positive probability that the incentive compatibility constraint binds in finite time, and the asymptotic distribution of allocations is not degenerate. For our argument to make empirical sense there must be enough variability in the shocks $\eta_{t} \cdot{ }^{7}$

\subsection{Additional sources of observed heterogeneity}

We have thus far assumed time-invariant utility functions (except $\eta_{t}$ ) and a stationary resource process. Suppose now that the utility is $u\left(c^{1} ; x_{t}^{1}\right)$ and $v\left(c^{2} ; x_{t}^{2}\right)$. Suppose also that resources depend on state $s_{t}$ and that a state variable $q_{t}$ describes the information set. Letting $x_{t}=\left(x_{t}^{1}, x_{t}^{2}\right)$, suppose that $\left(x_{t}, q_{t}\right)$ follows a Markov process whose realization is revealed to the agents at the beginning of period $t$. Then the value functions at date $t$ are functions $P\left(V ; x_{t}, q_{t}\right)$ and

\footnotetext{
${ }^{6}$ This follows from the fact that at the solution of the sub-program with a given contract, both $c_{s}^{2}$ and $V(s)$ are non-decreasing with $\mu$ and non-increasing with $\tau(e)$.

${ }^{7}$ See Thomas and Worrall (1988), Beaudry and DiNardo (1991) and Ray (2002). We thank a referee for this point and the references.
} 
$Q\left(V ; x_{t-1}, q_{t-1}\right)$. The value function $Q$ is the maximum

$$
E\left\{\chi_{t} \hat{P}\left(V_{t} ; x_{t}, q_{t}\right) \mid x_{t-1}, q_{t-1}\right\}
$$

subject to $E\left\{V_{t} \mid x_{t-1}, q_{t-1}\right\} \geq V$. The value function $P\left(V ; x_{t}, q_{t}\right)$ is equal to the maximum of

$$
E\left[u\left(c^{1}\left(x_{t}, q_{t}, s_{t}\right) ; x_{t}^{1}\right)+\rho Q\left(V\left(x_{t}, q_{t}, s_{t}\right) ; x_{t}, q_{t}\right) \mid x_{t}, q_{t}\right]
$$

subject to incentive and participation constraints. All proofs generalize to this set-up. The function $\bar{\mu}$ depends only on $\omega_{t}, \pi_{t}$ and $x_{t}, q_{t}$, but not on $\chi_{t}$, while the ratio of marginal utility has to be conditioned on $x_{t}^{i}$ only. We thus obtain

$$
\frac{u^{\prime}\left(c_{t}^{1} ; x_{t}^{1}\right)}{v^{\prime}\left(c_{t}^{2} ; x_{t}^{2}\right)}=\min \left\{\mu_{t}, \bar{\mu}\left(\omega_{t}, \pi_{t} ; x_{t}, q_{t}\right)\right\} .
$$

The contract $\bar{T}\left(\mu_{t} ; x_{t}, q_{t}\right)$ depends on $\mu_{t}$ and $x_{t}, q_{t}$ and the dynamics of the multiplier $\mu_{t}$ are unchanged.

\section{The Structural Econometric Model}

The main purpose of constructing an empirical model from these theoretical underpinnings is to test whether it leads to an empirically credible alternative to the perfect insurance and the limited commitment cases and to assess the degree of discrepancy with those. The new insight that our theoretical set-up brings about is that we should analyze the income process in addition to consumption growth. If income were exogenous, the hypothesis of complete markets would be tested by looking at the significance of the correlation between the residuals of the consumption growth equation and income. This procedure is correct since income is excluded from the marginal utility of consumption if leisure and consumption are separable. In our case, the choice of formal contracts makes income endogenous and there are indeed three endogenous variables (consumption, formal contracts and income). A test procedure that markets are complete should now be looking for exogenous or predetermined variables that affect formal contracts, thus income, and are independent of random preference shocks. ${ }^{8}$ Moreover, the absence of formal contracts, the case of pure limited commitment, is evaluated by testing for income exogeneity. Nevertheless, we want to achieve more than simply testing null hypotheses and this section focuses on formalizing an econometric model suited to the theory developed in the previous section and that can be identified using household panel data on income and consumption. Alternatives have been proposed in the literature to understand the empirical evidence that we obtain but we defer the discussion of their relevance until the empirical section.

\footnotetext{
${ }^{8}$ The issue of income endogeneity is dealt with in some papers in a reduced-form setting (e.g. Jacoby and Skoufias, 1998, Jalan and Ravallion, 1999).
} 
Some discussion of the most striking omissions is nonetheless in order. The first issue concerns the adaptation of the two-agent framework to a village i.e. a multi-agent framework. We follow Ligon et al. (2002) by assuming that each household plays a two-person game with the rest of the village or with a pivotal person in the village. The characteristics and the equilibrium realizations of endogenous variables of the other agent are written as village-and-period indicators.

The second issue is that we do not model individual savings or "investment" technologies that would enable households to transfer resources from one period to the next in an idiosyncratic way. As demonstrated by Ligon et al. (2000), the manipulation of incentive constraints becomes intractable in empirical applications. The level of aggregate savings is assumed to be determined by some unmodeled mechanism and captured by village-and-period dummy variables in the empirical model.

Third, we use information on consumption and income only. It is difficult to tell in the data whether contracts are formal so that we only capture their impact through the income process. Furthermore, we refrain from using information on informal transfers as Foster and Rosenzweig (2001) do because it seems difficult to us to draw a precise line between truly exogenous transfers and those that result from the very endogenous informal contracts that we model here. Consumption growth would eventually include those informal transfers (Deaton, 1997).

For the sake of clarity and for lack of a better device, we shall adopt the convention that "observable" refers from now on to variables which we, the econometrician, observe and we keep the expression "revealed at time $t$ " to designate what households observe at time $t$. Moreover, we shall adopt the following notation:

\section{Notation 3.1:}

(i) All parameters indexed by "vt" control for village-and-period effects.

(ii) Household i's consumption at time $t$ is denoted $c_{i t}$.

(iii) Household i's agricultural profits at time $t$, net of input costs including non family labor costs, are denoted $\pi_{i t}^{a}$. Household $i$ 's income at time $t$, including income from formal contracts, is denoted $\pi_{i t}=\pi_{i t}^{a}+\pi_{i t}^{e}$ where $\pi_{i t}^{e}$ is other income. The latter stands for other non-labor income or exogenous transfers such as remittances from abroad (excluding informal transfers).

(iv) Observed preference shifters (household demographics for instance) and unobserved preference shocks, respectively denoted $x_{i t}$ and $\eta_{i t}$, are revealed to agents at the beginning of period $t$.

(v) Besides taste shifters, the information set at the beginning of the period contains observed variables $q_{i t}$ (such as owned land) that are revealed to agents at the beginning of period $t$.

(vi) Income shocks are revealed at mid-period. Observed shocks ${ }^{9}$ are denoted $z_{i t}$ (days of illness

\footnotetext{
${ }^{9}$ In the theoretical model, we should assume that $z_{i t}$ and $\left(x_{i t}, q_{i t}\right)$ are independent. If they are not, we would
} 
and craft income for instance), unobservable shocks are denoted $\xi_{i t}$. The set of all observables at mid-period is denoted $m_{i t}=\left(x_{i t}, q_{i t}, z_{i t}\right)$.

We start below with the specification of utility functions, of formal contracts and of income processes. We continue by stating the identifying restrictions. All specification assumptions and restrictions are piled up into different items of Assumption 3.2. A proposition stating semiparametric identification follows and the section closes by explaining the estimation method by penalized splines.

\subsection{The Specification of Consumption and Income Equations}

\subsubsection{Consumption Dynamics}

Following most papers in this literature (exceptions are Ogaki and Zhang, 2001, for HARA estimation and Dubois, 2000, for heterogenous CRRA functional forms) we assume that households have constant relative risk aversion and that other goods, such as leisure, are excluded:

Assumption 3.2(i): The ratio of marginal utility of consumption for household $i$ at time $t$, relatively to the marginal utility of the village, $v$, is written as

$$
\eta_{i t} \frac{u_{i t}^{\prime}\left(c_{i t}\right)}{u_{v t}^{\prime}\left(c_{v t}\right)}=\eta_{i t} \exp \left(\delta_{v t}\right) \exp \left(\sigma x_{i t} \beta\right) \cdot c_{i t}^{-\sigma}
$$

where $\sigma>0$ and where the log of the marginal utility of the village is captured by the villageand-period effect $\delta_{v t}$. We denote $\lambda_{i t}(\beta)=\ln \left(c_{i t}\right)-x_{i t} \beta$ the adjusted consumption index.

Write the multiplier $\mu_{i t}$ defined in equation (21) and specified by the marginal utility (22), as:

$$
\ln \mu_{i t}=-\ln \chi_{i t}-\sigma \lambda_{i t-1}(\beta)+\delta_{v t-1},
$$

where the first difference shocks is given by $\ln \chi_{i t}=\ln \eta_{i t}-\ln \eta_{i t-1}$. Consumption dynamics is derived from the Euler equation (20) and the multiplier definition (23). Whether the incentive constraint facing household $i$ is binding or not defines two regimes:

$$
\begin{array}{r}
-\sigma \lambda_{i t}(\beta)+\delta_{v t}=\ln \bar{\mu}_{v t}\left(\pi_{i t}, x_{i t}, q_{i t}\right) \\
\text { if }-\ln \chi_{i t}-\sigma \lambda_{i t-1}(\beta)+\delta_{v t-1}>\ln \bar{\mu}_{v t}\left(\pi_{i t}, x_{i t}, q_{i t}\right) \\
-\sigma \lambda_{i t}(\beta)+\delta_{v t}=-\ln \chi_{i t}-\sigma \lambda_{i t-1}(\beta)+\delta_{v t-1} \\
\text { if }-\ln \chi_{i t}-\sigma \lambda_{i t-1}(\beta)+\delta_{v t-1}<\ln \bar{\mu}_{v t}\left(\pi_{i t}, x_{i t}, q_{i t}\right)
\end{array}
$$

where the notation $\bar{\mu}_{v t}$ replaces $\bar{\mu}$ in the Euler equation (20) because aggregate resources are now captured by the village-and-period index (Notation 3.1).

replace $z_{i t}$ by the innovation in $z_{i t}$ independent of $\left(x_{i t}, q_{i t}\right)$ that is by the unanticipated income shock. 
The functional form of the bound, $\ln \bar{\mu}_{v t}\left(\pi_{i t}, x_{i t}, q_{i t}\right)$, will be specified later on. Yet it should be noted immediately that this bound is deterministic. It could implicitly be made random if preference shifters and information variables $\left(x_{i t}, q_{i t}\right)$ were allowed to include some unobserved heterogeneity components. The structure of stochastic shocks however is already sufficiently rich because of the income variable $\pi_{i t}$. As we allow for measurement errors in income, the absence of unobserved heterogeneity in $\left(x_{i t}, q_{i t}\right)$ does not seem to be such a tight assumption in this model. ${ }^{10}$

Because we cannot observe whether the incentive constraint is binding or not, the two regimes cannot be distinguished. As a consequence, the system of equations above is observationally equivalent to a single equation describing the dynamics of consumption:

$$
\sigma \Delta \lambda_{i t}(\beta)=\Delta \delta_{v t}+\phi_{i t} \cdot \mathbf{1}\left\{\phi_{i t} \geq 0\right\}+\ln \chi_{i t},
$$

where:

$$
\phi_{i t}=\delta_{v t-1}-\sigma \lambda_{i t-1}(\beta)-\ln \chi_{i t}-\ln \bar{\mu}_{v t}\left(\pi_{i t}, x_{i t}, q_{i t}\right) .
$$

Two remarks are in order. First, complete markets is an interesting special case in which the incentive constraints never bind. We have, $\phi_{i t}<0$, so that the usual Euler equation holds:

$$
\Delta \ln c_{i t}=\Delta x_{i t} \beta+\left(\Delta \delta_{v t}+\ln \chi_{i t}\right) / \sigma .
$$

More generally, the existence of self-enforcing constraints implies that dynamics is sometimes consistent with the predictions derived from the hypothesis of complete markets and sometimes not, depending on the sign of $\phi_{i t}$.

Secondly, when the incentive constraint is binding, the second term in the right hand side of the Euler equation (24) is positive. It means that consumption growth is more than what would be expected under full insurance. It is the "rent" to pay to keep the household in the self-enforced informal arrangement when the income shock in the period is "too" favorable for the household.

Variable $\phi_{i t}$ depends on the income process $\pi_{i t}$ that we now detail.

\subsubsection{Formal Contracts and the Income Process}

A formal contract is described by equation (19) in Proposition 4. The vector of formal transfers (i.e. in any state $e$ ) is a function of the multiplier $\mu_{i t}$ and of variables belonging to the information set $\left(x_{i t}, q_{i t}\right)$ :

$$
\tau_{i t}=\tau_{v t}\left(-\ln \chi_{i t}-\sigma \lambda_{i t-1}(\beta)+\delta_{v t-1}, x_{i t}, q_{i t}\right),
$$

when the multiplier $\ln \mu_{i t}$ is replaced by its specification using equation (23). We have in mind that formal transfers $\tau_{i t}$ can be supported by land-leasing contracts (in or out) such as sharecropping contracts and their sharing rules or fixed-rent contracts for which the rent is fixed at

\footnotetext{
${ }^{10} \mathrm{~A}$ more difficult issue that we do not deal with here, is the presence of unobserved household effects in $x_{i t}, q_{i t}$. Yet, household effects are notoriously difficult to handle in non-linear dynamic settings although some advances could be made along the lines proposed by Cunha, Heckman and Navarro (2005).
} 
the village level. Reduced-form estimation indeed showed that such contracts do help sharing risks (Dubois, 2000). By contrast, it seems dubious that labor contracts can be formally enforced since permanent labor contracts are infrequently observed in village economies (see Bliss and Stern, 1982).

As a consequence, agricultural profits is a function of the characteristics of these contracts and in particular of the marginal utility of consumption $\mu_{i t}$ and of variables in the information set $\left(x_{i t}, q_{i t}\right)$. It is also a function of observed and unobserved income shocks $z_{i t}$ and $\xi_{i t}$ that are revealed after the signature of the contracts so that the reduced form of agricultural income is (using $m_{i t}=\left(x_{i t}, q_{i t}, z_{i t}\right)$, see Notation 3.1):

$$
\pi_{i t}^{a}=\pi^{a}\left(-\ln \chi_{i t}-\sigma \lambda_{i t-1}(\beta)+\delta_{v t-1}, m_{i t}, \xi_{i t}\right)
$$

We could have specified a structural production function or the structural relationships between the quantities of land under sharecropping and fixed-rent contracts and marginal utility. Given the complicated endogenous structure of land exploitation, this would be fraught with severe robustness issues.

Household net income is not only composed of agricultural profits but also of non-agricultural profits or other income, $\pi_{i t}^{e}$. For more generality, we also include $\pi_{i t}^{e}$ among variables $z_{i t}$ (Notation $3.1(\mathrm{vi})$ ), on top of adding it to $\pi_{i t}^{a}$. By adding some measurement errors, $\varsigma_{i t}$, and adopting the semiparametric assumption that agricultural profits are a linear function, we finally obtain measured income $\tilde{\pi}_{i t} \equiv \pi_{i t}^{a}+\pi_{i t}^{e}+\varsigma_{i t}$ as:

\section{Assumption 3.2(ii):}

$$
\tilde{\pi}_{i t}=\pi_{v t}+\pi_{0} \sigma \lambda_{i t-1}(\beta)+m_{i t} \pi_{m}+\pi_{0} \ln \chi_{i t}+\xi_{i t}+\varsigma_{i t} .
$$

where the village-and-period effect, $\pi_{v t}$, absorbs parameters $\delta_{v t-1}$.

Corollary 5 implies that parameter $\pi_{0}$ is positive which provides the first restriction of our model.

The equations describing consumption growth and income, (24) and (26), form our structural model. Assumptions about shocks and incentive constraints can now be spelled out.

\subsection{Identifying Restrictions and Reduced Forms}

Notation 3.1 and the consumption growth and income equations (24) and (26) lead to the following list of covariates, $w_{i t}=\left(\ln c_{i t-1}, x_{i t-1}, x_{i t}, q_{i t}, z_{i t}\right)$ respectively standing for lagged consumption, lagged and current preference shifters, information variables and other income shocks. Identifying restrictions on heterogeneity terms, measurement error and predetermined variables are stated as: 
Assumption 3.2 (ct'd): (iii) The vector of unobserved shocks in preferences and income $\left(\ln \chi_{i t}, \xi_{i t}\right)$ is independent of covariates $w_{i t}$ and of measurement errors, $\varsigma_{i t}$, and is identically distributed and independent across households and periods. It has an absolutely continuous distribution and its support is a compact set of $\mathbb{R}^{2}$.

(iv) Measurement error $\varsigma_{i t}$ is mean-independent of covariates, $w_{i t}$, and is independent across households and periods.

(v) Variables in $w_{i t}=\left(\ln c_{i t-1}, x_{i t-1}, x_{i t}, q_{i t}, z_{i t}\right)$ have a compact support in $\mathbb{R}^{r}$. If $w_{v t}=$ $E\left(w_{i t} \mid v, t\right)$ denotes their expectations within a village-and-period, there is full within-variation of the covariates i.e.:

$$
\operatorname{rank}\left(E\left[\left(w_{i t}-w_{v t}\right)\left(w_{i t}-w_{v t}\right)^{\prime}\right] \mid v, t\right)=r
$$

The independence assumption 3.2(iii) is slightly stronger than the ones generally used in linear dynamic models. Non-linearities, due here to the presence of a bound, require more than mean-independence assumptions. We also used the assumption of compact support in order to facilitate the proof of identification. Assumption 3.2(iv) is weaker as it takes advantage of linearity. Both assumptions 3.2 (iii \& iv) make the covariate process $w_{i t}$ weakly exogenous. Assumption $3.2(\mathrm{v})$ implies that the distribution function of predetermined variables $w_{i t}$ is not degenerate. This assumption is substantive since it would be violated if the information set does not include at least one variable $q_{i t}$ which is excluded from preferences (an asset variable for instance). Such variables provide exogenous variability in income.

The final step to complete the specification of consumption dynamics is to specify the bound $\phi_{i t}$ appearing in equation (25). As income $\pi_{i t}$, without measurement errors as described in Assumption 3.1(iii), depends on marginal utility, $\ln \chi_{i t}+\sigma \lambda_{i t-1}(\beta)-\delta_{v t-1}$ and on the index, $\pi_{v t}+m_{i t} \pi_{m}+\xi_{i t}$, the unobserved variable $\phi_{i t}$ defined in equation (25) can be written as a function of the following arguments:

$$
\phi_{i t}=\phi\left(\ln \chi_{i t}+\sigma \lambda_{i t-1}(\beta)-\delta_{v t-1}, \pi_{v t}+m_{i t} \pi_{m}+\xi_{i t}, x_{i t}, q_{i t}, \phi_{v t}\right)
$$

where $\phi_{v t}$ is a village-and-period effect. Using the independence assumption 3.2(iii), we can evaluate the conditional expectation of the non-linear term $\phi_{i t} \mathbf{1}\left\{\phi_{i t} \geq 0\right\}$ of the consumption growth equation (24) :

$$
\begin{aligned}
E\left(\phi _ { i t } \mathbf { 1 } \left\{\phi_{i t} \geq\right.\right. & \left.0\} \mid \ln c_{i t-1}, x_{i t-1}, x_{i t}, q_{i t}, z_{i t}\right) \equiv \\
& H\left(\lambda_{i t-1}(\beta)-\delta_{v t-1} / \sigma, \pi_{v t}+m_{i t} \pi_{m}, x_{i t}, q_{i t}, \phi_{v t}\right),
\end{aligned}
$$

where the positive function $H$ is derived from the joint distribution function of $\left(\ln \chi_{i t}, \xi_{i t}\right)$. 
We did not follow this non-parametric route $^{11}$ and chose to specify the bound as a linear index:

Assumption 3.2 (ct'd): (vi) $\ln \bar{\mu}_{v t}\left(\pi_{i t}, x_{i t}, q_{i t}\right)$ is linear in all its arguments.

We then have:

Lemma 6 Under Assumption 3.2 (vi), $\phi_{i t}$ is linear in all its arguments:

$$
\phi_{i t}=-\sigma\left(1+\pi_{0} \frac{\partial \ln \bar{\mu}_{v t}}{\partial \pi_{i t}}\right)\left(\lambda_{i t-1}(\beta)+m_{i t} \phi_{m}+\phi_{v t}\right)+\varepsilon_{i t}^{0}\left(\chi_{i t}, \xi_{i t}\right)
$$

Furthermore:

$$
E\left(\phi_{i t} \mathbf{1}\left\{\phi_{i t} \geq 0\right\} \mid \ln c_{i t-1}, x_{i t-1}, x_{i t}, q_{i t}, z_{i t}\right)=H\left(\lambda_{i t-1}(\beta)+m_{i t} \phi_{m}+\phi_{v t}\right)
$$

where $H($.$) is an unknown positive, decreasing, convex and twice differentiable function, where:$

$$
H^{\prime}\left(\lambda_{i t-1}(\beta)+m_{i t} \phi_{m}+\phi_{v t}\right)=-\operatorname{Pr}\left(\phi_{i t}>0\right) \cdot \sigma\left(1+\pi_{0} \frac{\partial \ln \bar{\mu}_{v t}}{\partial \pi_{i t}}\right)<0
$$

and if there is more than one z variable,

$$
\phi_{z^{(j)}} / \phi_{z^{(1)}}=\pi_{z^{(j)}} / \pi_{z^{(1)}} \text { for any } j>1 \text {. }
$$

Proof. See Appendix B.

Summarizing those results, the structural model consists of the following equations: First the consumption growth moment condition derived from equation (24) and equation (27) is:

$$
E\left(\sigma . \Delta \lambda_{i t}(\beta)-\Delta \delta_{v t} \mid \ln c_{i t-1}, x_{i t-1}, x_{i t}, q_{i t}, z_{i t}\right)=H\left(\lambda_{i t-1}(\beta)+m_{i t} \phi_{m}+\phi_{v t}\right) .
$$

Second, using equation (26), the income moment condition is:

$$
E\left(\tilde{\pi}_{i t} \mid \ln c_{i t-1}, x_{i t-1}, x_{i t}, q_{i t}, z_{i t}\right)=\pi_{v t}+\pi_{0} \sigma \lambda_{i t-1}(\beta)+m_{i t} \pi_{m}
$$

We allow for correlation between these equations. This correlation is not informative about the parameters of interest since it depends on the unrestricted joint distribution of random shocks.

We now study the identification of the system of structural equations (30) and (31).

\subsection{Semi-Parametric Identification}

The model depends on the following population parameters:

$$
\theta=\left(\sigma, \beta, \pi_{0}, \pi_{m}, \phi_{m}\right) \in \Theta, \quad \varrho=\left(\left\{\delta_{v t}, \pi_{v t}, \phi_{v t}\right\}_{v t}\right) \in \Xi, \quad H(.) \in \mathcal{H} .
$$

\footnotetext{
${ }^{11}$ The proof of identification remains however very similar in this more general case. It suffices to condition on $m_{i t}$ and village-and-period effects in the following.
} 
where $\theta$ is the parameter of interest. Village-and-period effects, $\varrho$, and the functional parameter $H($.$) are treated as nuisance parameters. The identification analysis proceeds as follows.$

First, parameter $\sigma>0$ is not identified since the intertemporal elasticity of substitution is not identified in an Euler equation when the interest rate is unknown. The two equations of interest are invariant to transforming the vector of parameters $\left(\sigma, \pi_{0}, \Delta \delta_{v t}, H().\right)$ into $\left(1, \pi_{0} / \sigma\right.$, $\left.\Delta \delta_{v t} / \sigma, H(.) / \sigma\right)$ (holding other parameters constant). We shall therefore normalize $\sigma=1$ and change the interpretation of other parameters accordingly.

Second, the parameters of the reduced form of the income equation (31), $\pi_{v t}, \pi_{0},-\beta \pi_{0}, \pi_{m}$ are identified because of the full rank assumption $3.2(\mathrm{v})$. This is the most one can get from the income equation. As $\pi_{0}$ and $-\beta \pi_{0}$ are identified, $\beta$ is identified which shows that, in the consumption growth equation (30), the dependent variable $\lambda_{i t}(\beta)=\ln c_{i t}-x_{i t} \beta$ is identified. The consumption equation,

$$
E\left(\Delta \lambda_{i t}(\beta) \mid \lambda_{i t-1}(\beta), m_{i t}\right)=\Delta \delta_{v t}+H\left(\lambda_{i t-1}(\beta)+m_{i t} \phi_{m}+\phi_{v t}\right)
$$

is an index model which identification is analyzed by Ichimura and Lee (1991). We adapt their assumptions to our special case as $H$ is a positive, decreasing and convex function (Lemma 6) and as all regressors are bounded. The main problem we have to face is that the intercept term is identified at infinity only (Heckman, 1990). We restrict function $H$ and its argument as follows:

\section{Assumption 3.2 (ct'd):}

(vii) For any $(v, t)$ and at the true parameter value, the support of $\lambda_{-1}+m \phi_{m}$, is a connected interval of $\mathbb{R}$. Denote $a_{1 v t}$ the value such that:

$$
\operatorname{Median}\left(\lambda_{-1}+m \phi_{m}+a_{1 v t}\right)=0
$$

The support of $\lambda_{-1}+m \phi_{m}+a_{1 v t}$ is denoted $S_{I}^{(v, t)}$.

(viii) $\mathcal{H}$ is the set of bounded, decreasing, convex and twice differentiable functions taking values on $\cup_{v, t} S_{I}^{(v, t)}$ and such that $H(0)=0$.

As shown in the proof of the next proposition, assumptions (vii \& viii) are normalizations if we observe one village at one period. The identification of $H$ follows from the normalization of its location and the location of its argument. Imposing these conditions for any village at any period is testable although the assumption is weak. In its absence, identification would not be robust to small departures from the other assumptions that $H($.$) does not directly depend on$ $v, t$ which would be generated by allowing for heteroskedasticity in $\xi_{i t}$ for instance. Finally, we cannot impose that function $H($.$) is positive.$

All these conditions are sufficient to obtain:

Proposition 7 Under Assumption 3.2 (i-viii), $(\theta, H)$ is identified in $\Theta \times \mathcal{H}$. 
Proof. See Appendix B

\subsection{Estimation using Penalized Splines}

To estimate the parameters of the consumption growth equation (32), we use penalized spline regression following $\mathrm{Yu}$ and Ruppert (2002). Letting $u=\lambda_{i t-1}(\beta)+m_{i t} \phi_{m}$, properly normalized using Assumption 3.2 (vii), we choose function $H($.$) in the following set:$

$$
H(u ; \gamma)=\gamma_{1} u+\ldots+\gamma_{p} u^{p}+\sum_{k=1}^{K-1} \gamma_{p+k} S_{p}\left(u-\kappa_{k}\right)
$$

where

$$
S_{p}\left(u-\kappa_{k}\right)=\left\{\begin{array}{l}
\left(u-\kappa_{k}\right)^{p} \mathbf{1}\left\{u>\kappa_{k}\right\} \text { for } k>p / 2 \\
\left(\kappa_{k}-u\right)^{p} \mathbf{1}\left\{u<\kappa_{k}\right\} \text { for } k \leq p / 2
\end{array}\right.
$$

where $\mathbf{1}\{A\}$ is the indicator function of $A$.

Parameters to estimate are $\left(\beta, \phi_{m},\left\{\Delta \delta_{v t}\right\}, \gamma\right)$ where $\left\{\Delta \delta_{v t}\right\}$ is the collection of village-andperiod effects and where $\gamma$ is the vector of parameters of the spline. The number of knots $K-1$ is considered fixed (see Ruppert, 2002, for a procedure of selection) and the locations of the knots $\kappa_{k}$ are supposed to be given by the $1 / K$-quantiles of $u$. By construction $H(0)=0$.

The estimation method consists of finding the global minimum of:

$$
Q\left(\beta, \phi_{m},\left\{\delta_{v t}\right\}, \gamma\right)=\sum_{i, t}\left(\Delta \lambda_{i t}(\beta)-\Delta \delta_{v t}-H\left(\lambda_{i t-1}(\beta)+m_{i t} \phi_{m} ; \gamma\right)\right)^{2}+\nu \cdot \gamma^{\prime} G \gamma
$$

where $\nu$ is a penalty weight. We chose to penalize equally the elements $\gamma_{p+1}$ to $\gamma_{p+K-1}$ writing:

$$
\gamma^{\prime} G \gamma=\sum_{k=1}^{K-1} \gamma_{p+k}^{2}
$$

so that we do not impose that function $H($.$) is decreasing and convex. The reader is referred to$ $\mathrm{Yu}$ and Ruppert (2002) for all proofs of asymptotic properties including the sandwich formula for the variance-covariance matrix of estimates. ${ }^{12}$

\section{The Empirical Analysis}

\subsection{Data Description and Economic Analysis}

The data come from a survey conducted by IFPRI (International Food Policy Research Institute) in Pakistan between 1986 and 1989 (see Alderman and Garcia, 1993, for a thorough presentation) whose information is roughly equivalent to the famous ICRISAT dataset. The survey consists of

\footnotetext{
${ }^{12}$ Other details concerning the algorithm, the choice of the smoothing parameter $\nu$ by generalized crossvalidation and the choice of other regularization parameters are presented in the working paper version (Dubois et al., 2005).
} 
a random sample of around 900 households interviewed 12 times and coming from four districts in three regions. This rich data set conveys information on household demographics, incomes from various sources, individual labor supply, endowments and owned assets, agrarian structure, crops and productions, and land contracts such as sharecropping and fixed rent.

Our endogenous variables are income and consumption growth. Sources of income are wages, agricultural profits, rents from property rights and pensions. Agricultural profits are computed at each survey round using the information since the previous round and consist of cash income from staples, milk products, animal poultry and livestock production, net of total input expenditures including non-family wage costs, feeding costs of productive animals, fertilizers and pesticides. Whether or not family labor costs should be substracted from agricultural profits is evaluated below. Other sources of income such as household's handicraft income, asset income - including property rents, fixed pensions regularly received from the government and rentals of other assets - and non-agricultural labor income are considered as "other income". Household wage income in off-farm agricultural tasks are considered as one of the support of informal transfers and is not included in income. Concerning the consumption variable, we choose food expenditures as our consumption variable because they represent the largest part of non-durable expenditures and are well measured. More details on the consumption variables are given in Appendix $\mathrm{C}$ and descriptive statistics are presented in Table 1.

In our model, observed heterogeneity between households are of different types: Preferences, $x$, other variables in the information set, $q$, or unanticipated shocks $z$. First, Dubois (2000) showed using the same data that household size is the main preference shifter. Other variables such as the number of children never proved to be significant. As for variables in the information set, various empirical analyses (see Jalan and Ravallion, 1999, for instance) report evidence that contrasting rich and poor households is the main relevant differentiation when the complete markets hypothesis is evaluated. As income is endogenous in our model, the quantity of owned land is a good indicator of a household's productive assets and a predetermined predictor of income. The quantity of owned rainfed land gives additional information about the quality of productive land. These two variables constitute the information set, denoted $q_{i t}$ above. Third, craft or trade profits or spells of illness of household members are unlikely to be contractible and are regarded as a component of unexpected income shocks, $z_{t}$.

Decomposing the variance of agricultural income into the village-and-period variance, the household variance and a residual one, confirms that rural households are mostly affected by large idiosyncratic risks. It is also true for other sources of income like asset income, wages and other income. In contrast, $52.7 \%$ of the variance of the logarithm of food expenditures comes from village-and-period effects and $23.7 \%$ from household effects. The first component refers to 
aggregate shocks, the second to the relative economic status of the household in the village, i.e. its Pareto weight. We find the same pattern when looking at expenditures corrected by household size or at total expenditures. Turning to first differences in the logarithm of food expenditures, we find substantial though quite imperfect risk sharing since village-time effects explain $24.1 \%$ of these changes, and household effects explain $2.2 \%{ }^{13}$ Of course, the variance decomposition of marginal utility also depends on preference shifters and first differencing magnifies measurement errors. Nevertheless, testing whether income shocks affect consumption growth controlling for preference shifters allowed one of the authors to reject perfect risk sharing using this dataset (Dubois, 2000).

Finally, the land rental market is very active in these villages since we observe in the data that the per period rate of change of area under contract such as sharecropping and fixed rent is $20 \%$ on average. This statistic provides a lower bound for the frequency of contract changes because we are not able to observe with whom the household contracted or contractual changes that did not involve a change in the land area under contract. This confirms that these contracts, which are natural candidate empirical counterparts for our formal contracts, are subject to frequent renegotiation.

\subsection{Structural Estimates}

When interpreting the results of the estimation of the income and consumption growth equations that are presented below, we shall examine the empirical relevance of the following testable structural restrictions:

$C 1: \pi_{0} \geq 0:$ monotonicity of the contract with respect to lagged marginal utility as derived from Corollary 5.

$C 2$ : The coefficients of preference shifters $x_{i t-1}$ in the income equation, and in both linear indices of the consumption growth equation, are all equal to $\beta$.

$C 3: H$ is decreasing.

There are also other restrictions derived from auxiliary econometric assumptions in Assumptions 3.2 (i-viii) that we directly describe in the text.

\subsubsection{The Income Equation}

We present several sets of estimation results of the income equation (26) in Table 2. As predicted by our model, the significance of the coefficient of lagged consumption in the income equation

\footnotetext{
${ }^{13}$ At the district level, risk sharing is significantly less effective and it is why we decided to pursue the analysis at the village level.
} 
provides some evidence that households smooth income. In column 1, we report two stage least squares estimates. This procedure controls for the presence of measurement error in lagged consumption by introducing residuals of the instrumental regression of lagged consumption on other variables of the regression and a further lag of consumption. The estimated coefficient of those residuals is indeed significant and is three times larger than the OLS estimate of the coefficient of lagged consumption. We also tested for the presence of measurement errors in the other variables using lags and we did not reject their exogeneity. A robustness analysis to econometric assumptions is detailed in Section 4.2 .3 below.

In conformity with restriction $\mathrm{C} 1$, the coefficient of lagged consumption $\pi_{0}$ is positive and significant. We also tried to use total expenditures with quite similar results. Yet, competing explanations that we now detail could be consistent with this result.

Household superior information If all relevant information is not included in the income equation, the significantly positive coefficient of lagged consumption in the income equation could also reflect lagged consumption being a good indicator of the information that households have about future income shocks that we, as analysts, do not observe. If households have superior information, income and lagged consumption are indeed positively correlated.

In order to investigate the importance of this effect, we use, as proposed by Campbell (1987), another decision variable that might reveal the superior information that households have on future income shocks under the assumption that this information is single dimensional. To be on par in terms of information with contractual decisions, this decision should be coincident with the signature of contracts. Net-rented in area ${ }^{14}$ is such a candidate variable since it is a productive factor. We regress net rented-in area on variables that are known at the beginning of the period and we interpret residuals as a measure of the superior information that households have. Table A.1 reports results of this estimation. The regression is very well determined and lagged consumption, which is instrumented as before, negatively affects rented-in area. Note that it is because lagged consumption is instrumented that residuals indeed contain new superior information if any.

In the second column of Table 2, the residual of the rented-in land equation used as information controls is found to be significant. Households have superior information and, as the coefficient is negative, tend to rent-in more land in anticipation of an adverse shock in income either in off-farm or on-farm activities. Our prediction C1 of a positive effect of lagged consumption is nevertheless robust to the presence of superior information. The estimated coefficient of lagged consumption remains significant and positive although it decreases marginally.

\footnotetext{
${ }^{14}$ or equivalently cultivated land as owned land is controlled for.
} 
Nutrition effects on productivity The positive effect of lagged consumption on income could also be due to nutrition effects on future productivity since more food consumption can help improve the productivity of agricultural laborers as analyzed by Behrman, Foster and Rosenzweig (1997) and Fafchamps and Quisumbing (1999). Both articles use working samples extracted from the same survey as us.

When planting labor effort is incompletely rewarded in the labor market and the productivity of labor is assumed to depend on current consumption, Behrman et al. (1997) argue that planting stage calories positively affect harvest stage profits. Using a subsample of wheat producers at two pairs of planting and harvest periods, they report empirical evidence about this positive relationship.

The availability of data on calorie intakes at the household level actually allows us to distinguish a nutrition effect from the mechanism of risk sharing though formal contracting. As expected, calorie consumption and food expenditures are correlated although we found no effect of lagged calorie intakes on income when we use this variable along with or instead of food expenditures. ${ }^{15}$ For instance, column 3 of Table 2 shows that when lagged food expenditures and lagged calorie intakes are both included in the estimation, the coefficient of lagged expenditures only is significantly different from zero. When using only lagged calorie intakes without food expenditures, the former estimated coefficient is not significant. The discrepancy with the results cited above might come from differences in the sample selection and construction of the data. In particular, by using all periods, we show that harvest stage consumption has an impact on the next planting stage profits as well. This is difficult to reconcile with a pure nutrition effect on productivity. As an aside, independent variation of food expenditures and calories reveal that preferences over food matter more for households than the productive rôle of food through calorie intakes.

As nutrition could have longer term effects, we also use information about the body mass index - weight over height squared - of household members. This variable is positively correlated with food calorie intakes. Introducing the average or total body mass index of household adults, or of male adults only, as additional variables, does not change the main results and shows a small positive but insignificant effect on productivity (column 4 of Table 2). This is in line with Fafchamps and Quisumbing (1999) who find that such impacts are small.

Labor market imperfections Our construction of agricultural profits in the income equation assumes that the labor market is imperfect. We do not substract family labor costs from agricultural profits so that we implicitly assume that there are no substitutes for family labor on

\footnotetext{
${ }^{15}$ As lagged food expenditures, lagged calorie intakes are instrumented by the second lag of calorie intakes because of measurement errors.
} 
the market. A polar assumption would be that labor markets are perfect. As a consequence, the construction of agricultural profits should be modified and they should be computed net of family labor costs. This is what we did by using village-level information on male and female wages at each period as well as male and female hours of work to impute family labor costs. The income equation results hardly change and if any effect, the coefficient of lagged consumption in the income equation is larger by a non significant factor of $10 \%$. We also repeated the analysis substracting either male or female labor costs with no change.

Other determinants Regarding the estimated coefficients of other variables in Table 2, household demographics should partly compensate the effect of lagged consumption, and lagged household size indeed does, though insignificantly. The quantity of owned land affects household income although rainfed land compensates it so that their difference, irrigated land, only seems to matter. A larger number of days of illness for males and females decreases income as expected though insignificantly. Informal transfers could take the form of additional labor from the village that compensate for the sickness of household members since it might be less costly to intervene at that stage than afterwards (Fafchamps, 1992). Sickness would not affect household income in that case but the way we construct income would be contaminated by informal transfers that are implicitly already smoothing it. Errors in self-reporting wealth is another possible explanation (Strauss and Thomas, 1998) but our data limitations preclude any further analysis of these arguments. Finally, other income is positive and very significant. We tested and did not reject the exogeneity of this variable, using the various individual income components as instruments.

\subsubsection{Consumption Growth Equation}

In Table 3, we report the estimates of the consumption growth equation using penalized spline regressions. The number of knots of the spline is small and equal to 8 and the penalization parameter is optimally chosen by Generalized Cross Validation for the specification corresponding to column 1.

We estimate the system of income and consumption growth equations by allowing for some correlation between equations. This correlation is insignificant in magnitude (0.001) and statistically. The likelihood ratio statistic contrasting estimations allowing or not for correlated equations is equal to 0.4 and has one degree of freedom. It shows that even if residual shocks in income are correlated with the residuals of consumption growth through incentive constraints, the influence of these shocks is small relative to measurement errors in both equations and preference shocks in consumption dynamics. We do not report the estimates of the income equation because they are very similar to what is reported in Table 2.

As before, we follow a control function approach in non-linear models (see Blundell and Powell, 
2003) and we introduce, as an explanatory variable, the residual of the regression of lagged consumption on its second lag and all other variables to take into account the measurement errors in lagged consumption. Consumption exogeneity is rejected very strongly indeed and the magnitude of the estimated coefficient denotes the presence of large measurement errors in consumption. In column 2 we also introduce the residual of the net rented-in area equation (Table A-1) as a control for superior information. It is very significant (the likelihood ratio statistic for the system of equations is around 60 and has two degrees of freedom) though it does not affect the estimation of the other coefficients.

We now consider testing the restrictions C2 and C3. First, the hypothesis that the coefficients of preference variables in the consumption and income equations are equal (C2) cannot be rejected. The likelihood ratio statistic is equal to 1.4 in column 2 of Table 3 . It has two degrees of freedom although we should account for the fact that we were unable to precisely estimate the coefficients of lagged household size in both linear indices because function $H()$ is close to a linear function (see below). Nevertheless, even if $H()$ is linear and the statistic has one degree of freedom only, we cannot reject restriction (C2) at any reasonable level of confidence.

Figure 1 reports estimates of the function $H($.$) using optimal smoothing. Although it should$ not be taken as a formal test, its shape is not in contradiction with hypothesis (C3) as it is decreasing. Incentive constraints bind with some strictly positive probability and the model is statistically able to capture the type of market incompleteness at work in this economy. Moreover, recall from equation (28) that the slope of $H($.$) is the product of the probability that an incentive$ constraint is binding multiplied by $1+\pi_{0} \frac{\partial \ln \bar{\mu}_{v t}}{\partial \pi_{i t}}>0$. As $\frac{\partial \ln \bar{\mu}_{v t}}{\partial \pi_{i t}}<0$ (see Appendix B), the slope is a lower bound on this probability and a rough estimate of this probability is equal to 0.15 .

We analyze the most complete results of Table 3, Column 2, by starting with parameters in the linear index of the equation of consumption growth. As expected, household size has a positive and significant effect on the marginal utility of consumption in a way that is comparable to what was obtained in a more usual setting (Dubois, 2000). It is more difficult to analyze the effects of variables in the linear index which is the argument of function $H($.$) . Remember that$ the larger this index is, the smaller is the probability that the incentive constraint binds. Positive coefficients indicate that we are moving away from the constraint. It is only the case for variables such as male days of illness (though the effect is insignificant) and for information controls that we have seen to be negatively correlated to income (Table 2). It is negative for household size, land assets, female days of illness and other income. Intuitively, we should expect that beneficial income shocks should increase the probability that the incentive constraint binds.

Nevertheless, theory does not completely comfort these insights because there could be compensating effects due to the information, correlated with these variables that affect the contracting 
choices of the household. It is what is observed, however, for all variables except for female days of illness which is an intriguing result. As already mentioned, the issue that days of illness can be immediately compensated by informal transfers of labor seems to us to be an interesting way to explore. Moreover days of illness could affect function $H($.$) in a more complicated way if the as-$ sumption of independence (A3.2(iii)) in this regressor is violated. As a matter of fact we did test another consequence of independence (A3.2(iii)) in unexpected income shocks (equation (29)) and we were able to reject this restriction. More complicated dependence of $H$ on $z_{t}$, stemming from heteroskedasticity of $\xi_{i t+1}$ for instance, should thus be allowed for.

As residual variances in income are larger after the first half of the sample period (see below), we split the sample into two periods and re-estimated the consumption growth equation. Results are reported in the two last columns of Table 3 and are very stable across sub-samples although many estimates lose their significance. In Table A-2, we report tests of the separability of consumption and leisure obtained by regressing the residuals of the consumption growth equation on male and female labor supply variables. None are significant and we do not reject separability.

\subsubsection{Robustness analysis}

A thorough analysis of serial correlation and sensitivity to auxiliary parameters used in penalized spline regression is presented in Dubois et al. (2005) and we briefly summarize it now.

Serial Correlation in Incomes Analyzing the autocorrelation of unobservables affecting income, we found that during the sample period, two subperiods can be distinguished, the first one with small variances (till round 7 ), the second one with a lot more variance. Alderman and Garcia (1993) report that the sample period was a quite uncertain and troubled period for agricultural activities, yet it seems to be true above all for the second half of the sample period.

This overall view does not indicate the presence of strong household specific effects. We also tried to first-difference the income equation but we lost all significance. The main question that remains is whether households are aware of the structure of autocorrelation because we use econometric restrictions that they are not. More prosaically, the presence of serial correlation might also modify standard errors of the estimates of the income equation. We did try to correct for serial correlation by assuming that it is unrestricted over time but constant across individuals. It indeed modified standard errors of coefficients though by a maximal factor of $50 \%$ without affecting any diagnostic of significance that was used using the robust to heteroskedasticity White correction (Table 2).

Serial Correlation in Consumption Growth We computed the residual variances of the consumption growth equation along with their autocorrelations. In contrast to income residuals, 
there is no clear time pattern for consumption residual variance, only two peaks at rounds 6 and 9. They might be attributed to measurement errors since the length of the period is somewhat variable across rounds even though we considered weekly income and consumption levels. The pattern of autocorrelation is more surprising since first-order correlation varies between -0.2 and 0.05, second-order correlation between -0.17 and 0 , third-order correlation between 0 and 0.10 and fourth-order correlation between 0.05 and 0.15 . In the case in which the function $H($.$) is$ linear, we develop in Dubois et al. (2005) a model with i.i.d. preference shocks and classical measurement errors and we calibrate it on our data. Autocorrelation coefficients are broadly in line with the empirical ones. The calibration also shows that the magnitude of preference shocks and measurement errors are roughly equal in the residuals of the consumption growth equation.

Other auxiliary parameters The auxiliary parameters in penalized spline regression are the penalization parameter, the number of knots and the order of the spline. The income equation is not affected by the variations in these parameters as correlation between equations is virtually equal to zero.

Making the penalization parameter vary between one tenth of its optimal value and ten times its optimal value produces no noticeable difference on estimated coefficient values but only differences in estimated standard errors for some coefficients. We tested structural restrictions by using likelihood ratio statistics which are more robust than Wald tests. We also ran the same kind of experiment by varying the number of knots and the order of the splines. In all cases, the central results of this paper remain the same though standard errors seem affected by those auxiliary parameters. Regarding the estimates of function $H($.$) when the order of the$ spline varies, it is much smoother using quadratic and cubic splines although the estimation using linear splines does not contradict our main empirical conclusions.

Spatial correlation We also estimated auxiliary regressions of cross-products of income residuals and of cross-products of consumption growth residuals within a village on the absolute difference between households of characteristics such as land assets or household size. These regressions are intended to investigate whether unexplained components of consumption growth and income are associated across households of similar characteristics in each village. Results are reported in Table A-3. Interestingly the cross-product of residuals is always a negative function of the distance of characteristics between households. Furthermore, while the distance in land assets have a strong influence on the cross-product between income residuals, their influence is much attenuated in the consumption growth equation. This is not the case for the distance in household size. In the absence of household fixed effects, it is tempting to interpret these results as consistent with partial risk sharing of productivity shocks attached to asset levels but no risk 
sharing of demographic shocks.

\section{Discussion \& Extensions}

We elaborated a theoretical setting which nests the case of complete markets when all risk can be insured by formal contracts and the case in which only informal agreements are available. Its empirical implementation builds upon the estimation of an Euler equation of consumption dynamics and an income equation using data from village economies in Pakistan.

Overall, our results indicate that those villages are far from the case of perfect risk sharing in which lagged consumption would explain neither income nor consumption growth or from the case of limited commitment in which lagged consumption would not explain income. Both cases are rejected in significant way. The importance of formal contracts and limited commitment can be evaluated from the empirical estimates of the two structural equations. First, from results in Table 2, we can derive that $12 \%$ of the within-village variance of income is explained by lagged consumption and lagged preference shifters and we have been arguing that this comes from formal contracting. Specifically, while information variables including land assets explain four times as much as "other income", formal contracts are on a par with "other income" in terms of explaining the total within-village variance of agricultural profits. Income smoothing due to formal contracting is thus economically significant. Second, we can also evaluate the explanatory power provided by limited commitment and formal contracts in the consumption growth equation although it is low, as usual with consumption growth. Whereas $24 \%$ of the variance of consumption growth is explained by village-and-period effects, only $1.6 \%$ is explained by the non linear function $H($.$) and its arguments and 0.3 \%$ by preference shifters. Nonetheless, as incentive constraints do not bind at all periods, one in seven being the estimated lower bound of the frequency of its occurrence, the economic magnitude of such a result is still significant.

Policy evaluation by simulation would require full structural estimates, as discussed in the limitations below. Nonetheless, we can already draw interesting policy implications.

First, by providing evidence on the impact of informal agreements, our work points to important but often neglected mechanisms interlinking formal and informal agreements. This is in line with evidence on contract interlinkages (Bell, 1988). One consequence is that short term land agreements react to future anticipated shocks in a non trivial way, since anticipations affect the incentives to renege on informal agreements. Our analysis also corroborates evidence explaining in part the success of micro-credit that relies on similar informal mechanisms.

Moreover, the dimension of informal risk sharing should be incorporated both into the evaluation and into the design of development programs. Specifically, the policy designer should evaluate whether an intervention complements informal agreements or weakens the ability of 
agents to cooperate. In the latter case, gains in terms of access to new instruments or markets should outweigh the cost in terms of lost commitment. As Albarran and Attanasio (2003) show, policies that aims at improving formal risk sharing could crowd out informal mechanisms.

Furthermore, the focus on commitment issues also suggests designing policies that improve the enforceability of contracts within communities, prior to extending the set of contractual parties (e.g. governments, banks, international institutions ...). It may also be desirable to adjust interventions at the local level, with field studies aiming at identifying and exploiting channels of informal risk sharing. Localized programs may in particular aim at identifying the credible parties (able to commit), and associating them to policy.

Much remains to be done before one can draw a complete picture of the role of informal agreements in village economies. In a companion paper (Dubois et al., 2002), we analyze a model in which no agent can commit. Conclusions about contract monotonicity are preserved although the dynamics of the ratio of marginal utility is affected by a second threshold which corresponds to the incentive constraint of agent 2 .

Besides, although here we focused attention on short-term contracts, our theoretical and empirical conclusions should extend to the case of longer but finite horizon contracts, provided that these contracts can be renegotiated every period at no cost. What really matters is the ability to use contracts to affect the distribution of the outside options of the agents. Long term contracts can be used to affect the continuation utility of deviating agents, and then can be renegotiated (including voluntary cancellation of contracts) to improve the efficiency of the future relationship.

It was out of the scope of the paper to try to identify structural correspondence functions between the space of contracts and the marginal rate of substitution of consumption between two successive periods. It is nevertheless high on the research agenda since it would lead to full structural modelling allowing simulation of the impact of economic policies. Whereas we posited a reduced form for modeling the incentive compatibility constraint, the precise determination of which contracts can be enforced would lead to the determination of the full structure. This line of research would certainly involve simplifying the description of risks that households face and contracts that they can use. Our analysis provides support for the relevance of our setting thereby encouraging to attempt such a construction.

The issue of saving, and more generally of any device linking one period to the next (nutrition, investment in agricultural technology,...) is difficult to address. Some recent progress has been made by Gobert and Poitevin (2006) in the case of public savings. They assume that breaching an informal agreement triggers the loss of the saving assets. It would make sense in our context if the asset was borne by the agent who is able to commit. Beyond consumption smoothing, 
savings provide resources that can be used as collateral of informal promises and that help relax incentive constraints. When savings are publicly monitored but privately owned, it would affect the outside options of a deviant agent and would also raise convexity issues (see Ligon et al., 2000). Another critical issue is asymmetric information when savings are not publicly observed. As pointed up by Cole and Kocherlakota (2001), hidden savings drastically limit the ability to use even formal contracts.

\section{REFERENCES}

Abreu, D. (1988): "On the Theory of Infinitely Repeated Games with Discounting", Econometrica, 56, 383-396.

Albarran, P. and O., Attanasio (2003): "Limited commitment and crowding out of private transfers: evidence from Mexican villages", Economic Journal, 113, 77-C85.

Alderman, H., and M. Garcia (1993): Poverty, household food security, and nutrition in rural Pakistan. Research Report 96. Washington, D.C.: International Food Policy Research Institute.

Attanasio, O., and J. V. Ríos-Rull (2003): "Consumption Smoothing and Extended Families", Advances in Economics and Econometrics: Theory and Applications, Volume III, 209-242.

Beaudry, P., and J. DiNardo, (1991): "The effect of implicit contracts on the movement of wages over the business cycle: evidence from micro data", Journal of Political Economy, 665-688.

Behrman, J.R., A. Foster and M., Rosenzweig, (1997), "The dynamics of agricultural production and the calorie-income relationship: evidence from Pakistan", Journal of Econometrics, $77: 187-207$.

Bell, C. (1988), "Credit Markets, Contracts and Interlinked Transactions", in H. Chenery and T.N. Srinivasan, (eds.), Handbook of Development Economics, Amsterdam: North Holland Vol. 1, Chap. 16, 763-830.

Benveniste J., and J. Scheinkman (1979): "On the differentiability of the value function in dynamic models of economics", Econometrica, 47:727-32.

Bliss, C., and N. Stern (1982): Palampur: The Economy of An Indian Village, Oxford UP, Oxford.

Blundell, R., L. Pistaferri and I. Preston (2003): "Consumption Inequality and Partial Insurance", unpublished manuscript.

Blundell, R., and J. Powell (2003): "Endogeneity in Non Parametric and Semi Parametric Regression Models", Advances in Economics and Econometrics: Theory and Applications, Volume II:312-57.

Campbell, J. Y. (1987): "Does saving anticipate declining labor income?", Econometrica, 55, 1249-1273 
Coate, S., and M. Ravallion (1993): "Reciprocity without commitment - Characterization and Performance of Informal Insurance Arrangements", Journal of Development Economics, 40, $1-24$

Cole, H., and N. R. Kocherlakota (2001): "Efficient Allocations with Hidden Income and HiddenStorage", Review of Economic Studies, 68, 523-542.

Cunha, F., J.J., Heckman and S., Navarro (2005): "Separating Uncertainty from Heterogeneity in Life-Cycle Earnings", Oxford Economic Papers, 57(2), 191-261.

Deaton, A. (1997): The Analysis of Household Surveys, The World Bank, John Hopkins: Baltimore.

Dercon, S. (2004): Insurance against Poverty, Oxford U.P.

Doepke M. and R. Townsend (2006): "Dynamic Mechanisms Design with Hidden Income and Hidden Actions", Journal of Economic Theory, 106, 235-285.

Dubois, P. (2000): "Assurance Parfaite, Hétérogénéité des Préférences et Métayage au Pakistan", Annales d'Economie et de Statistique, 59, 1-36.

Dubois, P., B. Jullien and T. Magnac (2002): "Risk Sharing with Formal and Informal Contracts: Theory, Semi-Parametric Identification and Estimation", unpublished manuscript.

Dubois, P., B. Jullien and T. Magnac (2005): "Formal and Informal Risk Sharing in LDCs: Theory and Empirical Evidence", IDEI Working Paper 351.

Fafchamps, M. (1992): "Solidarity Networks in Pre-Industrial Societies: Rational Peasants with a Moral Economy", Economic Development and Cultural Change, 41, 1, 147-174.

Fafchamps, M. (2003): Rural Poverty, Risk and Development, Edward Elgar Publishing, Cheltenham (UK)

Fafchamps, M., and A., Quisumbing, (1999): "Human Capital, Productivity and Labor Allocation in Rural Pakistan", The Journal of Human Resources, 34:369-406.

Foster, A. and M., Rosenzweig (2001): "Imperfect Commitment, Altruism and the Family: Evidence from Transfer Behavior in Low-Income Rural Areas", Review of Economics and Statistics, 83, 3, 389-407.

Gauthier, C., M., Poitevin, and P., Gonzalez (1997): "Ex-ante payments in self enforcing risk sharing contracts", Journal of Economic Theory, 76, 106-144.

Heckman, J.J. (1990): "Varieties of Selection Biases", American Economic Review, 80, 313-318.

Ichimura, H., and L.F. Lee (1991): "Semiparametric Least Squares Estimation of Multiple Index Models : Single Equation Estimation" in Non Parametric and Semiparametric Methods in Econometrics and Statistics, ed. by W.A. Barnett, J. Powell and G. Tauchen, Cambridge UP: Cambridge.

Jacoby, H. G., and E., Skoufias (1998): "Testing Theories of Consumption Behavior Using Information on Aggregate Shocks: Income Seasonality and Rainfall in Rural India", American Journal of Agricultural-Economics, 80, 1, 1-14.

Jalan, J., and M. Ravallion (1999): "Are the Poor Less Well Insured? Evidence on Vulnerability to Income Risk in Rural China", Journal of Development Economics, 58, 1, 61-81.

Kocherlakota, N. (1996): "Implications of Efficient Risk Sharing without Commitment", Review of Economic Studies, 63, 595-609.

Koeppl, T. (2006): "Differentiability of the Efficient Frontier when Commitment to Risk Sharing is Limited", Topics in Macroeconomics, 6(1):Art. 10.

Ligon, E., J. Thomas and T. Worrall (2000): "Mutual Insurance, Individual Savings and Limited Commitment", Review of Economic Dynamics, 3, 1-47. 
Ligon, E., J. Thomas and T. Worrall (2002): "Mutual Insurance and Limited Commitment: Theory and Evidence in Village Economies", Review of Economic Studies, 69, 209-244.

Milgrom, P., and Shannon C. (1994): "Monotone Comparative Statics", Econometrica, $62,1,157-80$.

Morduch, J. (1995): "Income Smoothing and Consumption Smoothing" Journal of Economic Perspectives; 9(3), 103-114.

Morduch, J. (1999): "Between the State and the Market: Can Informal Insurance Patch the Safety Net?" World Bank Research Observer; 14(2), 187-207.

Newbery, D. (1977) "Risk Sharing, Sharecropping and Uncertainty Labor Markets", Review of Economic Studies, 44, 3, 585-594

Ogaki, M., and Q. Zhang (2001): "Decreasing Relative Risk Aversion and Tests of Risk Sharing", Econometrica, 69, 515-526.

Ray, D. (2002): "The Time Structure of Self-Enforcing Agreement", Econometrica, 70, 547-582.

Rockafellar (1970): Convex Analysis Princeton, N.J., Princeton University Press

Ruppert, D. (2002): "Selecting the Number of Knots for Penalized Splines", Journal of Computational and Graphical Statistics, 11(4), 735-57.

Stiglitz, J. (1974): "Incentives and Risk Sharing in Sharecropping", Review of Economic Studies, 41, 2, 219-255

Strauss J. and D. Thomas, (1998), "Health, Nutrition and Economic Development", Journal of Economic Literature, 36:766-817.

Thomas, J., and T. Worrall. (1988): "Self Enforcing Wage Contracts", Review of Economic Studies, 55, 541-554.

Thomas, J., and T. Worrall. (1990): "Income Fluctuation and Asymmetric Information: an Example of Repeated Principal-Agent Problem", Journal of Economic Theory, 51, 367-390.

Townsend, R. (1994): "Risk and Insurance in Village India", Econometrica 62(3), 539-591.

Udry, C. (1994): "Risk and Insurance in a Rural Credit Market: An Empirical investigation in Northern Nigeria", Review of Economic Studies, 61, 3, 495-526.

Yu, Y., and D. Ruppert (2002): "Penalized Spline Estimation for Partially Linear Single Index Models", Journal of the American Statistical Association, 97, 1042-54. 


\section{Tables \& Figure}

Table 1: Descriptive statistics ${ }^{16}$

\begin{tabular}{lcc}
\hline \hline Descriptive statistics (all periods, 8053 observations) & & \\
\hline Variable & Average & Std. Err. \\
\hline Food consumption & 176.29 & 103.21 \\
Other non durable expenditures (heating, ..) & 43.66 & 188.98 \\
Total owned land area (acres) & 9.42 & 21.81 \\
Land owner (0:landless, 1:owner) & 0.60 & 0.48 \\
Total Land Owned in Village (acres) & 6.66 & 13.2 \\
Irrigated land (acres) & 3.32 & 8.94 \\
Non irrigated land (acres) & 1.79 & 4.76 \\
Household size & 7.73 & 2.73 \\
Number of children ( $\leq 15 y e a r s)$ & 4.56 & 2.21 \\
Number of days of illness per week (male) & 0.52 & 1.75 \\
Number of days of illness per week (female) & 0.25 & 0.90 \\
Pensions & 18.76 & 199 \\
Agricultural profits & -169.0 & 656.7 \\
Transfers & 87.03 & 408.2 \\
Other income & 154.1 & 628.3 \\
Total income (without transfers) & 151.19 & 840.7 \\
Sharecropping dummy variable (renting in) & 0.35 & 0.47 \\
Fixed rent dummy variable (renting in) & 0.08 & 0.26 \\
Total area under sharecropping (renting in), (acres) & 2.65 & 4.96 \\
Total area under fixed rent (renting in), (acres) & 0.47 & 3.39 \\
Total area under sharecropping (renting out), (acres) & 2.55 & 9.84 \\
Total area under fixed rent (renting out), (acres) & 0.35 & 3.80 \\
\hline \hline
\end{tabular}

\footnotetext{
${ }^{16}$ All income and expenditure variables are in Rupees per week.
} 
Table 2: Income Equation ${ }^{17}$

\begin{tabular}{|c|c|c|c|c|}
\hline \multirow{2}{*}{$\begin{array}{l}\text { Dependent variable: } \tilde{\pi}_{i t} \\
\pi_{0}\end{array}$} & \multicolumn{4}{|c|}{ (2SLS) } \\
\hline & (1) & (2) & $(3)$ & (4) \\
\hline & 0.194 & 0.177 & 0.169 & 0.166 \\
\hline & $(0.060)$ & $(0.062)$ & $(0.061)$ & $(0.061)$ \\
\hline \multicolumn{5}{|l|}{$-\pi_{0} \beta$} \\
\hline lagged $(\log )$ household size & 0.032 & 0.035 & 0.013 & 0.016 \\
\hline & $(0.079)$ & $(0.079)$ & $(0.092)$ & $(0.092)$ \\
\hline \multicolumn{5}{|l|}{$\pi_{q}$} \\
\hline total land in village & 0.149 & 0.150 & 0.149 & 0.148 \\
\hline & $(0.016)$ & $(0.016)$ & $(0.016)$ & $(0.016)$ \\
\hline rainfed land in village & -0.195 & -0.193 & -0.195 & -0.195 \\
\hline & $(0.031)$ & $(0.031)$ & $(0.032)$ & $(0.032)$ \\
\hline \multicolumn{5}{|l|}{ (lop) bonold a } \\
\hline (log) household size & -0.129 & -0.125 & -0.133 & -0.134 \\
\hline \multicolumn{4}{|l|}{$x^{\prime}$} & \\
\hline female illness days & -0.004 & -0.005 & -0.005 & -0.005 \\
\hline & $(0.011)$ & $(0.011)$ & $(0.011)$ & $(0.011)$ \\
\hline \multirow[t]{2}{*}{ male illness days } & -0.008 & -0.008 & -0.009 & -0.008 \\
\hline & $(0.005)$ & $(0.005)$ & $(0.005)$ & $(0.005)$ \\
\hline \multirow[t]{2}{*}{ other income } & 0.159 & 0.157 & 0.157 & 0.157 \\
\hline & $(0.038)$ & $(0.036)$ & $(0.036)$ & $(0.036)$ \\
\hline Consumption Residuals & -0.135 & -0.116 & -0.112 & -0.109 \\
\hline (for $\ln c_{t-1}$ equation in lags) & $(0.064)$ & $(0.065)$ & $(0.064)$ & $(0.064)$ \\
\hline Information controls & & -0.005 & -0.005 & -0.005 \\
\hline (from rented-in land equation) & & $(0.002)$ & $(0.002)$ & $(0.002)$ \\
\hline \multirow[t]{2}{*}{ Lagged log-Calorie Consumption } & & & 0.040 & 0.04 \\
\hline & & & $(0.078)$ & $(0.078)$ \\
\hline \multirow[t]{2}{*}{ Lagged Adults Body Mass Index } & & & & 0.002 \\
\hline & & & & $(0.003)$ \\
\hline Observations & 7133 & 7133 & 7131 & 7131 \\
\hline
\end{tabular}

\footnotetext{
${ }^{17}$ Robust standard errors in parentheses. Village-and-period effects (46 villages, 11 rounds) not shown. $\ln c_{i t-1}$ is instrumented by $\ln c_{i t-2}$ and all other variables.
} 
Table 3: Consumption Growth ${ }^{18}$

\begin{tabular}{|c|c|c|c|c|}
\hline \multirow[b]{2}{*}{$\begin{array}{l}\text { Consumption Growth } \\
\quad \text { Linear index }\end{array}$} & \multicolumn{4}{|c|}{ System Estimation } \\
\hline & (1) & $(2)$ & $\begin{array}{c}(3) \\
\text { Round }<=7\end{array}$ & $\begin{array}{c}(4) \\
\text { Round }>=8\end{array}$ \\
\hline$\Delta \ln \left(h h_{-} \text {size }\right)_{t}: \beta$ & $\begin{array}{l}0.248 \\
(0.075)\end{array}$ & $\begin{array}{c}0.249 \\
(0.035)\end{array}$ & $\begin{array}{l}0.212 \\
(0.60)\end{array}$ & $\begin{array}{l}0.267 \\
(0.34)\end{array}$ \\
\hline Residual $\left(\ln c_{i t-1}\right)$ & $\begin{array}{l}-0.571 \\
(0.024)\end{array}$ & $\begin{array}{l}-0.565 \\
(0.024)\end{array}$ & $\begin{array}{l}-0.652 \\
(0.075)\end{array}$ & $\begin{array}{l}-0.505 \\
(0.040)\end{array}$ \\
\hline Linear argument of $H()$. & & & & \\
\hline $\ln c_{i t-1}$ & $\begin{array}{l}1 \\
(-)\end{array}$ & $\begin{array}{l}1 \\
(-)\end{array}$ & $\begin{array}{c}1 \\
(-)\end{array}$ & $\begin{array}{l}1 \\
(-)\end{array}$ \\
\hline$-\ln \left(h h_{-} \text {size }\right)_{t-1}: \beta$ & $\begin{array}{c}0.248 \\
(-)\end{array}$ & $\begin{array}{c}0.249 \\
(-)\end{array}$ & $\begin{array}{c}0.212 \\
(-)\end{array}$ & $\begin{array}{c}0.267 \\
(-)\end{array}$ \\
\hline $\ln \left(h h_{-} \text {size }\right)_{t}$ & $\begin{array}{l}-0.466 \\
(0.083)\end{array}$ & $\begin{array}{l}-0.458 \\
(0.15)\end{array}$ & $\begin{array}{l}-0.332 \\
(0.46)\end{array}$ & $\begin{array}{l}-0.435 \\
(0.17)\end{array}$ \\
\hline Owned Land & $\begin{array}{l}-0.020 \\
(0.006)\end{array}$ & $\begin{array}{l}-0.015 \\
(0.003)\end{array}$ & $\begin{array}{c}-0.032 \\
(0.0157)\end{array}$ & $\begin{array}{c}0.005 \\
(0.007)\end{array}$ \\
\hline Rainfed Land & $\begin{array}{l}-0.041 \\
(0.014)\end{array}$ & $\begin{array}{c}-0.052 \\
(0.0264)\end{array}$ & $\begin{array}{l}0.448 \\
(0.38)\end{array}$ & $\begin{array}{c}-0.173 \\
(0.30)\end{array}$ \\
\hline Female illness & $\begin{array}{l}-0.231 \\
(0.066)\end{array}$ & $\begin{array}{l}-0.220 \\
(0.062)\end{array}$ & $\begin{array}{l}-0.193 \\
(0.41)\end{array}$ & $\begin{array}{l}-0.203 \\
(0.070)\end{array}$ \\
\hline Male illness & $\begin{array}{c}0.008 \\
(0.0011)\end{array}$ & $\begin{array}{c}0.004 \\
(0.0085)\end{array}$ & $\begin{array}{c}0.013 \\
(0.0057)\end{array}$ & $\begin{array}{c}-0.038 \\
(0.0480)\end{array}$ \\
\hline Other income & $\begin{array}{c}-0.181 \\
(0.1367)\end{array}$ & $\begin{array}{c}-0.197 \\
(0.1426)\end{array}$ & $\begin{array}{c}-0.311 \\
(0.6563)\end{array}$ & $\begin{array}{c}-0.168 \\
(0.0249)\end{array}$ \\
\hline Information Control & & $\begin{array}{c}0.011 \\
(0.0016)\end{array}$ & $\begin{array}{c}0.034 \\
(0.0166)\end{array}$ & $\begin{array}{c}0.007 \\
(0.0031)\end{array}$ \\
\hline Likelihood & -850.0 & -829.6 & 204.8 & -809.8 \\
\hline Observations & 7133 & 7133 & 3704 & 3429 \\
\hline
\end{tabular}

\footnotetext{
${ }^{18}$ Quadratic splines. 8 knots. Penalization parameter $=1.69$. Robust standard errors below estimates in parenthesis. Village-and-period effects (46 villages, 11 rounds) not shown. $\ln c_{i t-1}$ is instrumented by $\ln c_{i t-2}$ and all other variables. Coefficients whose standard errors are (-) are normalized or set by a structural restriction.
} 


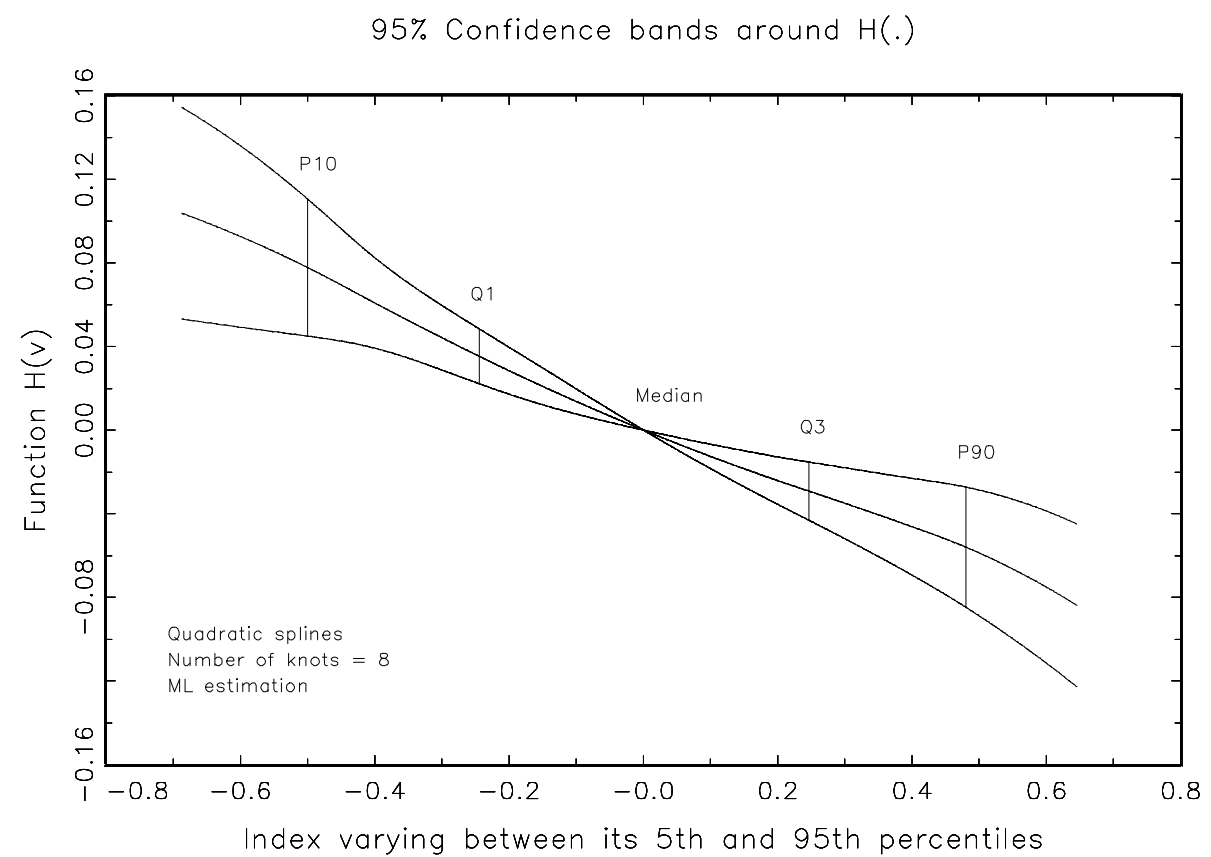

Figure 1: Quadratic Splines: Optimal Smoothing.

\section{A Appendix to Section 2}

Lemma $8 \hat{P}(V)$ is differentiable on $] \underline{V}, \bar{V}[$.

Proof. > From Carathéodory's Theorem (see Rockafellar (1970), corollary 17.1.5), the optimum obtains with a two-point support distribution, say $V_{\chi} \in\left\{V_{\chi}^{1}, V_{\chi}^{2}\right\}$ with probability $p$ and $1-p$. Thus an optimal allocation is such that conditional on $\chi$, the distribution of the future utility solves the program

$$
\hat{P}\left(V_{\chi}\right)=\max _{p \in] 0,1]}\left\{p P\left(V_{\chi}^{1}\right)+(1-p) P\left(V_{\chi}^{2}\right)\right\} \text { s.t. } p V_{\chi}^{1}+(1-p) V_{\chi}^{2}=V_{\chi} .
$$

For conciseness, we now focus on a point at which $P(V)=\hat{P}(V)$ so that there is no randomization and $p=1$, and consider the solution of program $P$. Notice that it must be the case that $\forall e \in \mathcal{E}, \tau(e) \leq 0$. Otherwise a reduction in $\tau(e)$ would raise the utility of agent 2 without affecting the other constraints. Notice also that given that $P$ is decreasing on $] \underline{V}, \bar{V}[$, the agent 1 receives a utility strictly larger than the autarky level for $V<\bar{V}$. As a consequence, the constraint (10) is not binding in at least one state $\hat{s}$, since otherwise the agent 1 could not receive more than the autarky level. Then, for $x$ small, consider the allocation obtained by simply adjusting $c^{2}(\hat{s})$ by $\gamma(x)$ such that $p_{\hat{s}}\left(v\left(c^{2}(\hat{s})+\gamma(x)\right)-v\left(c^{2}(\hat{s})\right)\right)=x$ and $c^{1}(\hat{s})$ to $c^{1}(\hat{s})-\gamma(x)$. The new utility of agent 1 is

$$
H(V+x)=\hat{P}(V)+p_{\hat{s}}\left(u\left(c^{1}(\hat{s})-\gamma(x)\right)-u\left(c^{1}(\hat{s})\right)\right) \leq \hat{P}(V+x)
$$


as the new allocation is feasible and yields $V+x$ to agent 2 . Moreover $H$ is concave and differentiable, and $H(V)=\hat{P}(V)$. From lemma 1 in Benveniste and Scheinkman (1979), the function $\hat{P}($.$) is differentiable$

Lemma $9 Q($.$) is strictly concave.$

Proof. First notice that for $V=0$, the solution is to set $\tau_{t}=0$ and $c_{t}^{1}=\omega_{t}$ at all dates so that $\hat{P}(0)=P(0)=\frac{1}{1-\rho} \sum_{s} p_{s} u\left(\omega^{1}(s)+\omega^{2}(s)\right)$ and no incentive constraint is binding. Given that $v^{\prime}(0)=+\infty$, we obtain $\hat{P}^{\prime}(0)=0>\hat{P}^{\prime}(\bar{V})$. Consider the set $B$ of slopes $b$ such that $b=-\hat{P}^{\prime}(V)$ occurs for more than one value $V$. The solution of $Q(V)$ is a function $\hat{V}(\chi)$ with

$$
\chi \hat{P}^{\prime}(\hat{V}(\chi))=Q^{\prime}(V) \text { if } \chi>\frac{Q^{\prime}(V)}{\hat{P}^{\prime}(\bar{V})}, \hat{V}(\chi)=\bar{V} \text { if } \chi \leq \frac{Q^{\prime}(V)}{\hat{P}^{\prime}(\bar{V})} .
$$

This defines $\hat{V}(\chi)$ uniquely except when $\frac{Q^{\prime}(V)}{\chi} \in B$, which occurs with zero probability since $B$ is a countable set and $\chi$ is a continuous random variable. Consider now $V^{\prime}>V$ with a solution $V^{\prime}(\chi)$. It is impossible that $Q^{\prime}\left(V^{\prime}\right)=Q^{\prime}(V)$ because this would imply $V^{\prime}(\chi)=V(\chi)$ with probability one and thus contradicts $E\left\{V^{\prime}(\chi)\right\}=V^{\prime}>V$. Thus $Q^{\prime}($.$) must be decreasing.$

\section{A.1 Proof of proposition 4}

We solve the program $\Phi(\mu)=\max _{T} \hat{\Phi}(\mu, T)$ where

$$
\begin{aligned}
\hat{\Phi}(\mu, T)= & \max _{\left(c^{1}(s), c^{2}(s), V(s)\right)_{s},} \sum_{s \in \mathcal{S}} p_{s}\left(u\left(c^{1}(s)\right)+\rho Q(V(s))+\mu\left[v\left(c^{2}(s)\right)+\rho V(s)\right]\right) \\
& \text { s.t }(10),(11),(12) .
\end{aligned}
$$

Lemma 10 There exists a function $\bar{\mu}(\omega, \pi)$ with values in $\left[-\hat{P}^{\prime}(\underline{V}),-\hat{P}^{\prime}(\bar{V})[\right.$, decreasing in $\pi$ whenever interior, such that the solution satisfies:

$$
\frac{u^{\prime}\left(c^{1}(s)\right)}{v^{\prime}\left(c^{2}(s)\right)}=-Q^{\prime}(V(s))=\min \{\mu, \bar{\mu}(\omega(s), \pi(s))\}
$$

Proof. Given the separability in $\tau(e)$, we can optimize events by events: $\hat{\Phi}(\mu, T)=$ $\sum_{e} p_{e} \Phi_{e}(\mu, \tau(e))$ where:

$$
\Phi_{e}(\mu, \tau(e))=\max _{\left(c^{1}(s), c^{2}(s), V(s)\right)} E\left[u\left(c^{1}(s)\right)+\rho Q(V(s)) \mid e\right]+\mu E\left[v\left(\omega(s)-c^{1}(s)\right)+\rho V(s) \mid e\right]
$$

s.t.

$$
\begin{aligned}
\left(\frac{p_{s}}{p_{e}} \lambda_{s}^{1}\right) \quad u\left(c^{1}(s)\right)+\rho Q(V(s)) & \geq u(\pi(s))+\rho \underline{v}^{1} \quad \forall s \in e \\
\left(\frac{p_{s}}{p_{e}} \rho \bar{\gamma}_{s}\right) \quad V(s) & \leq \bar{V} \\
\left(\frac{p_{s}}{p_{e}} \rho \underline{\gamma}_{s}\right) \quad \underline{V} & \leq V(s)
\end{aligned}
$$

where the terms in parentheses are Lagrange multipliers. The Lagrangian of the program is:

$$
\begin{aligned}
& \sum_{s \in e} \frac{p_{s}}{p_{e}}\left\{u\left(c^{1}(s)\right)+\rho Q(V(s))+\mu\left[v\left(\omega(s)-c^{1}(s)\right)+\rho V(s)\right]\right. \\
& \left.+\lambda_{s}^{1}\left[u\left(c^{1}(s)\right)+\rho Q(V(s))\right]+\left(\underline{\gamma}_{s}-\bar{\gamma}_{s}\right) \rho V(s)\right\}
\end{aligned}
$$


As the program is strictly concave, the first order conditions are necessary and sufficient for optimality. After elimination of $\underline{\gamma}_{s}, \bar{\gamma}_{s}$, they reduce to:

$$
\begin{aligned}
\frac{u^{\prime}\left(c^{1}(s)\right)}{v^{\prime}\left(c^{2}(s)\right)} & =\frac{\mu}{1+\lambda_{s}^{1}} \\
-Q^{\prime}(\bar{V}) & \leq \frac{\mu}{1+\lambda_{s}^{1}}(=\text { if } V(s)<\bar{V}) \\
\mu v^{\prime}\left(c^{2}(s)\right) & =u^{\prime}\left(c^{1}(s)\right)\left(1+\lambda_{s}^{1}\right) .
\end{aligned}
$$

Let $\phi($.$) be the (increasing) inverse function of -Q^{\prime}($.$) and \psi^{1}(\omega, \mu)$ be the solutions of

$$
\frac{u^{\prime}\left(\psi^{1}\right)}{v^{\prime}\left(\omega-\psi^{1}\right)}=\mu
$$

The solution coincides with $c^{1}(s)=\psi^{1}(\omega(s), \mu)$ and $V(s)=\phi(\mu)$ in all states where the incentive constraint is not binding:

$$
u\left(\psi^{1}(\omega(s), \mu)\right)+\rho Q(\phi(\mu)) \geq u(\pi(s))+\rho \underline{v}_{1} .
$$

The LHS of the condition decreases with $\mu$. Define $\bar{\mu}(\omega, \pi)$ as the solution of equation (A.4) holding with equality. Then $\bar{\mu}(\omega, \pi)$ decreases with $\pi$, and the incentive constraint is not binding whenever $\mu \leq \bar{\mu}(\omega(s), \pi(s))$.

Now suppose that $\mu \geq \bar{\mu}\left(\omega(s), \omega^{1}(s)+\tau(e)\right)$. Then $\frac{u^{\prime}\left(c^{1}(s)\right)}{v^{\prime}\left(c^{2}(s)\right)}=-Q^{\prime}(V(s))=\bar{\mu}(\omega(s), \pi(s))=$ $\frac{\mu}{1+\lambda_{s}^{1}}$ satisfies the first order conditions and thus is the solution.

Lemma 11 The mapping $\bar{T}(\mu): \mu \rightarrow \arg \max _{T} \hat{\Phi}(\mu, T)$ is a monotone non-increasing correspondence in $\mu$ (according to the strong order set).

Proof. We can restrict attention to the subset $\tau(e) \leq 0$ where $\frac{\partial \varphi_{e}}{\partial \tau(e)} \leq 0$. The result follows from Milgrom and Shannon (1994), Theorem 4. Given the separability in $\tau(e), \hat{\Phi}(\mu, T)$ is quasisupermodular in $T$. The following lemma shows that it also satisfies the single crossing condition in $(T ; \mu)$.

Lemma 12 For a.e. $\tau(e), \frac{1}{\mu} \frac{\partial \hat{\Phi}(\mu, T)}{\partial \tau(e)}$ is non-increasing with $\mu$, decreasing if (10) is binding in some state of event $e$.

Proof. > From the envelope theorem, at any point where $\operatorname{Pr}\left\{\omega^{1}(s)+\tau(e)=0 \mid e\right\}=0$, and thus for all except a finite number of values of $\tau(e)$, we have

$$
\frac{\partial \Phi_{e}(\mu, \tau(e))}{\partial \tau(e)}=-E\left\{\mu v^{\prime}\left(c^{2}(s)\right) \frac{\partial \varphi(e, \tau(e))}{\partial \tau(e)}+\lambda_{s}^{1} u^{\prime}\left(\omega^{1}(s)+\tau(e)\right) \mid e\right\}
$$

Denote by $\hat{\psi}(\mu, \omega)$ the solution of

$$
\hat{\psi}=u^{\prime}(x)=\mu v^{\prime}(\omega-x)
$$


When $\mu>\bar{\mu}$, then $\lambda_{s}^{1}=\frac{\mu}{\bar{\mu}(\omega(s), \pi(s))}-1$ and $\mu v^{\prime}\left(c^{2}(s)\right)=\frac{\mu}{\bar{\mu}} \hat{\psi}(\bar{\mu}, \omega(s))$. When $\mu<\bar{\mu}$, then $\lambda_{s}^{1}=0$ and $\mu v^{\prime}\left(c^{2}(s)\right)=\hat{\psi}(\mu, \omega(s))$. Thus

$$
\begin{aligned}
& \frac{\partial \Phi_{e}(\mu, \tau(e))}{\partial \tau(e)}=-E\left\{\hat{\psi}(\mu, \omega(s)) \frac{\partial \varphi(e, \tau(e))}{\partial \tau(e)} \mid \mu<\bar{\mu}, e\right\} \operatorname{prob}(\mu<\bar{\mu} \mid e) \\
& \quad-E\left\{\frac{\mu}{\bar{\mu}} \hat{\psi}(\bar{\mu}, \omega(s)) \frac{\partial \varphi(e, \tau(e))}{\partial \tau(e)}+\left(\frac{\mu}{\bar{\mu}}-1\right) u^{\prime}\left(\omega^{1}(s)+\tau(e)\right) \mid \mu>\bar{\mu}, e\right\} \operatorname{prob}(\mu>\bar{\mu} \mid e)
\end{aligned}
$$

This function is differentiable in $\mu$ for all $\mu$ such that $\bar{\mu}$ is not equal to $\mu$ with probability 1 . Otherwise the argument which follows applies to the right and left derivative in $\mu$. We have:

$$
\begin{aligned}
& \mu \frac{\partial}{\partial \mu}\left(\frac{\partial \Phi_{e}(\mu, \tau(e))}{\partial \tau(e)}\right)=-E\left\{\mu \frac{\partial \hat{\psi}(\mu, \omega(s))}{\partial \mu} \frac{\partial \varphi(e, \tau(e))}{\partial \tau(e)} \mid \mu<\bar{\mu}, e\right\} \operatorname{prob}(\mu<\bar{\mu} \mid e) \\
& -E\left\{\frac{\mu}{\bar{\mu}} \hat{\psi}(\bar{\mu}, \omega(s)) \frac{\partial \varphi(e, \tau(e))}{\partial \tau(e)}+\frac{\mu}{\bar{\mu}} u^{\prime}\left(\omega^{1}(s)+\tau(e)\right) \mid \mu>\bar{\mu}, e\right\} \operatorname{prob}(\mu>\bar{\mu} \mid e) \\
& \mu \frac{\partial}{\partial \mu}\left(\frac{\partial \Phi_{e}(\mu, \tau(e))}{\partial \tau(e)}\right)=\frac{\partial \Phi_{e}(\mu, \tau(e))}{\partial \tau(e)} \\
& +E\left\{\left(\hat{\psi}(\mu, \omega(s))-\mu \frac{\partial \hat{\psi}(\mu, \omega(s))}{\partial \mu}\right) \frac{\partial \varphi(e, \tau(e))}{\partial \tau(e)} \mid \mu<\bar{\mu}, e\right\} \operatorname{prob}(\mu<\bar{\mu} \mid e) \\
& \left(\hat{m}-E\left\{u^{\prime}\left(\omega^{1}(s)+\tau(e)\right) \mid \mu>\bar{\mu}, e\right\} \operatorname{prob}(\mu>\bar{\mu} \mid e)\right.
\end{aligned}
$$

As

$$
\hat{\psi}-\mu \frac{\partial \hat{\psi}}{\partial \mu}=\mu v^{\prime}\left(1-\frac{u^{\prime \prime}}{u^{\prime \prime}+\mu v^{\prime \prime}}\right)>0
$$

and $\frac{\partial \varphi_{e}}{\partial \tau(e)} \leq 0$, we have

$$
\mu \frac{\partial}{\partial \mu}\left(\frac{\partial \Phi_{e}(\mu, \tau(e))}{\partial \tau(e)}\right) \leq \frac{\partial \Phi_{e}(\mu, \tau(e))}{\partial \tau(e)} .
$$

Equality arises only if $\operatorname{prob}(\bar{\mu}>\mu \mid e)=1$ and $\tau(e)=0$, which means that the incentive constraints is not binding.

This shows that for a.e. $\tau(e): \frac{\partial}{\partial \mu}\left(\frac{1}{\mu} \frac{\partial \hat{\Phi}}{\partial \tau(e)}\right)=\frac{\partial}{\partial \mu}\left(\frac{1}{\mu} p_{e} \frac{\partial \Phi_{e}}{\partial \tau(e)}\right)=\frac{p_{e}}{\mu^{2}}\left(\mu \frac{\partial}{\partial \mu}\left(\frac{\partial \Phi_{e}}{\partial \tau(e)}\right)-\frac{\partial \Phi_{e}}{\partial \tau(e)}\right) \leq 0$, with equality only if the incentive constraint is never binding in event $e$.

Proof of proposition 4. Condition (19) follows from lemma 11, condition (20) follows from Lemma (10), and condition (21) follows from Lemma (10) and condition (16). The set of values where $\bar{T}(\mu)$ is not singled values is countable since $\bar{T}(\mu)$ is increasing with a compact support. From the argument of lemma 9 , the probability that a $\mu_{t}$ belongs to this set is zero. 


\section{B Appendix to Section 3}

\section{B.1 Lemma 6}

Using equation (25) and the linearity of $\ln \bar{\mu}_{v t}$ by Assumption 3.2(vi), simple algebra delivers the first statement:

$$
\begin{aligned}
\phi_{i t}= & -\sigma\left(1+\pi_{0} \frac{\partial \ln \bar{\mu}_{v t}}{\partial \pi_{i t}}\right) \lambda_{i t-1}(\beta)-x_{i t}\left(\frac{\partial \ln \bar{\mu}_{v t}}{\partial x_{i t}}+\pi_{x} \pi_{0} \frac{\partial \ln \bar{\mu}_{v t}}{\partial \pi_{i t}}\right) \\
& -q_{i t}\left(\frac{\partial \ln \bar{\mu}_{v t}}{\partial q_{i t}}+\pi_{q} \pi_{0} \frac{\partial \ln \bar{\mu}_{v t}}{\partial \pi_{i t}}\right)-z_{i t}\left(\pi_{z} \frac{\partial \ln \bar{\mu}_{v t}}{\partial \pi_{i t}} \pi_{0}\right)+\tilde{\phi}_{v t}+\varepsilon_{i t}^{0}\left(\chi_{i t}, \xi_{i t}\right) \\
= & -\sigma\left(1+\pi_{0} \frac{\partial \ln \bar{\mu}_{v t}}{\partial \pi_{i t}}\right)\left(\lambda_{i t-1}(\beta)+m_{i t} \phi_{m}+\phi_{v t}\right)+\varepsilon_{i t}^{0}
\end{aligned}
$$

where $\phi_{v t}$ is a linear combination of village-and-period effects and where $\varepsilon_{i t}^{0}$ is a linear combination of $\Delta \eta_{i t}$ and $\xi_{i t}$. $\varepsilon_{i t}^{0}$ is independent of any covariates $w_{i t}$ and is absolutely continuous by Assumption 3.2(iii). As a consequence, the second statement follows:

$$
E\left(\phi_{i t} \mathbf{1}\left\{\phi_{i t} \geq 0\right\} \mid w_{i t}\right)=E\left(\phi_{i t} \mathbf{1}\left\{\phi_{i t} \geq 0\right\} \mid \phi_{i t}^{0}\right)=H\left(\phi_{i t}^{0}\right)
$$

where $\phi_{i t}^{0}=\lambda_{i t-1}(\beta)+m_{i t} \phi_{m}+\phi_{v t}$ and function $H(x)$ is positive.

Furthermore $\left(1+\pi_{0} \frac{\partial \ln \bar{\mu}_{v t}}{\partial \pi_{i t}}\right)>0$ (although $\frac{\partial \ln \bar{\mu}_{v t}}{\partial \pi_{i t}}<0$ by Proposition 4 (ii)) because the ratio of marginal utility tomorrow, $\lambda_{i t+1}(\beta)$, is an increasing function of marginal utility today, $\lambda_{i t}(\beta)$, because of the strict concavity of function $Q($.$) .$

Moreover, function $H(x)$ is equal (up to a positive scale) to:

$$
H(x) \propto \int_{u>x}(-x+u) f(u) d u
$$

and thus:

$$
H^{\prime}(x) \propto-\operatorname{Pr}(u>x),
$$

which proves that $H($.$) is decreasing, convex and twice differentiable. The scale parameter is$ given by the coefficient of $\lambda_{i t-1}(\beta)$ in equation (B.2) which proves the third statement of the Lemma.

Finally, equation (B.1) implies the fourth statement that the coefficients of $z_{i t}$ are proportional to $\pi_{z}$.

\section{B.2 Proposition 7}

The only remaining parameters of interest to identify $\phi_{m}$ and $H()$ are in the consumption equation. We first show that Assumptions 3.2 (vii,viii) are normalizations at the village-and-period level. Then we show how $\phi_{m}$ and $H()$ are identified on the support $S_{I}^{(v, t)}$ and thus are globally identified.

Fix $v$ and $t$ and drop those indices. Write the consumption equation as:

$$
E\left(\Delta \lambda \mid \lambda_{-1}, m\right)=\Delta \delta+H\left(\lambda_{-1}+m \phi_{m}+\phi\right)
$$

As function $H$ is positive, decreasing and convex and as its argument $u=\lambda_{-1}+m \phi_{m}+\phi$ is bounded, this moment condition is invariant to transformations of $(\Delta \delta, \phi, H(u))$ into $(\Delta \delta+$ $\left.a_{0}, \phi+a_{1},-a_{0}+H\left(u-a_{1}\right)\right)$ where $\left(a_{0}, a_{1}\right)$ are any pair of scalars such that $a_{0}<\min _{u} H\left(u-a_{1}\right)$. 
Hence, $(\Delta \delta, \phi, H)$ is not identified and we can adopt any normalization $\left(a_{0}, a_{1}, H_{0}\right)$ for the true $(\Delta \delta, \phi, H)$. More precisely, we can normalize the location of $H($.$) and the location of its argument.$ Recall that by Assumption 3.2 (iii \& v), the variable $\lambda_{-1}$ is absolutely continuous and $\left(\lambda_{-1}, m\right.$ ) are bounded so that $\lambda_{-1}+m \phi_{m}+a_{1}$ is a bounded index which distribution is continuous on the support $S_{I}$. The support is connected by Assumption 3.2 (vii). Any quantile normalization such as the median in Assumption 3.2 (vii) implies that 0 is an interior point of $S_{I}$. Assumption 3.2 (viii) then posits that, at that value $0, H$ takes value 0 .

We now return to the proof of the Proposition. As function $H$ is bounded, decreasing and twice differentiable and as the index is continuous on $S_{I}, E\left(\Delta \lambda \mid \lambda_{-1}, m\right)$ necessarily continuously decreases from $c_{H}$ to $c_{L}$ (say) where $c_{L}<c_{H}$.

Conversely, for any $c \in\left[c_{L}, c_{H}\right]$, the set $S_{0}=\left\{\left(\lambda_{-1}, m\right)\right.$ such that $\left.E\left(\Delta \lambda \mid \lambda_{-1}, m\right)=c\right\}$ is defined and equal to a linear manifold $\lambda_{-1}+m \phi_{m}=b$. Therefore $\phi_{m}$ is identified because of Assumption $3.2(\mathrm{v})$. By Assumption 3.2(vii), $a_{1}=-\operatorname{Median}\left(\lambda_{-1}+m \phi_{m}\right)$. Denote $S_{0}$ the set of values of $\left(\lambda_{-1}, m\right)$, such that $\lambda_{-1}+m \phi_{m}+a_{1}=0$. Then, $a_{0}=E\left(\Delta \lambda \mid\left(\lambda_{-1}, m\right) \in S_{0}\right)$ is identified. For any value $b=\left(\lambda_{-1}+m \phi_{m}+a_{1}\right)$ in support $S_{I}$, we can then construct function $H$ as the function of $b$ such as:

$$
H(b)=E\left(\Delta \lambda \mid \lambda_{-1}+m \phi_{m}+a_{1}=b\right)-a_{0}
$$

and $H$ is identified in $S_{I}$.

Finally, as $\left(\phi_{m}, H\right)$ are identified at the village-and-period level, they are identified globally, $H()$ on the union of the previous sets which all contain 0.

\section{Data Appendix}

The data provided by IFPRI consist of a sample of 927 households (first round) interviewed 12 times between 1986 and 1989. The survey is realized in four districts in three regions (Attock and Faisalabad in Punjab, Badin in the Sind, and Dir in the North West Frontier Province). In each of the four districts, villages were randomly chosen from a comprehensive list of villages classified in three sets according to their distances to two markets (mandis), and, households were randomly drawn from a comprehensive list of village households. Some attrition is observed in the data ( 887 households in the final survey) that seems to stem from administrative and political problems rather than from self-selection of households (Alderman and Garcia, 1993). We shall assume that attrition is exogenous.

In the survey, household demographics are directly available. Household food consumption is initially reported by food item, in quantity and value, or quantity and price. It comprises meals at home including home-produced goods, and meals taken outside for all household members except meals that were the result of invitation or rewards in kind as the information on those items was not available. The non durable non food expenditures correspond mainly to heating expenditures. Other expenditures are related to travel, education, entertainment (very few), health, hygiene, clothes and tobacco, electricity and gas (some of which were missing in the sample for several periods). Transfers correspond to transfers received from relatives, friends and from solidarity funds of local mosques (zakat). 


\section{C.1 Tables}

Table A.1 : Rented-in land area ${ }^{19}$

\begin{tabular}{lcc}
\hline \hline & OLS & 2SLS \\
\hline Net rented-in area & $(1)$ & $(2)$ \\
\hline $\ln c_{t-1}$ & -1.807 & -5.323 \\
& $(0.275)$ & $(0.851)$ \\
$q_{i t}:$ land owned & & \\
total land in village & -5.192 & -5.054 \\
& $(0.237)$ & $(0.249)$ \\
rainfed land in village & -5.152 & -4.875 \\
& $(0.785)$ & $(0.837)$ \\
$x_{i t}:(\log )$ household size & 1.318 & 1.915 \\
& $(1.241)$ & $(1.340)$ \\
$x_{i t-1}:$ lag (log) household size & 1.735 & 2.523 \\
& $(1.256)$ & $(1.327)$ \\
Constant & 5.815 & 19.666 \\
& $(1.598)$ & $(3.754)$ \\
\hline Observations & 8053 & 7133 \\
\hline R-squared & 0.53 & \\
\hline \hline
\end{tabular}

\footnotetext{
${ }^{19}$ Robust standard errors in parentheses. All village-and-period effects (46 villages, 11 rounds) not shown. In the case of 2 SLS estimates, $\ln c_{i t-1}$ is instrumented by $\ln c_{i t-2}$ and all other variables.
} 
Table A.2: Consumption \& Leisure Separability

\begin{tabular}{llc}
\hline \hline Dependent Variable & \multicolumn{2}{c}{ Consumption-growth residuals } \\
\hline Explanatory Variables & Coeff. & Std. Error \\
& & \\
Male labor (days) & -0.0009 & $(0.0010)$ \\
Female labor (days) & -0.0045 & $(0.0024)$ \\
\hline Observations & & 7133 \\
\hline R-squared & 0.0007 \\
\hline \hline
\end{tabular}

Table A.3: Within-village Correlations of Income and Consumption Growth ${ }^{20}$

\begin{tabular}{lcccc}
\hline \hline & \multicolumn{2}{c}{$\begin{array}{c}\text { Within-village } \\
\text { Income Correlations }\end{array}$} & $\begin{array}{c}\text { Within-village Consumption } \\
\text { Growth Correlations }\end{array}$ \\
\hline Dependent Variable & Cross-product of residuals $(i, j)$ & Cross-product of residuals $(i, j)$ \\
\hline Explanatory Variables & Coeff. & Std. Error & Coeff. & Std. Error \\
$\left|x_{i t}-x_{j t}\right|$ & & $(0.0035)$ & -0.030 & $(0.0030)$ \\
total land in village & -0.140 & $(0.010)$ & -0.023 & $(0.0084)$ \\
rainfed land in village & -0.061 & $(0.012)$ & -0.21 & $(0.0095)$ \\
$\quad(\log )$ household size & -0.19 & 137561 & & 137561 \\
\hline Observations & & 0.024 & 0.0056 \\
\hline R-squared & &
\end{tabular}

\footnotetext{
${ }^{20}$ This is the regression of all cross-products of residuals of the income equation (or consumption growth equation) within each village and each period on the distance between explanatory variables. No correction for first stage estimation. Village-and-period effects are included and not shown.
} 